\title{
Design and growth of GaN-based blue and green laser diodes
}

\author{
Aiqin $\operatorname{Tian}^{1 \dagger}$, Lei $\mathrm{Hu}^{1,2 \dagger}$, Liqun Zhang ${ }^{1}$, Jianping Liu ${ }^{1,2^{*}}$ and Hui Yang ${ }^{1,2}$
}

\begin{abstract}
GaN-based laser diodes (LDs) extend the wavelength of semiconductor $L D s$ into the visible and ultraviolet spectrum ranges, and are therefore expected to be widely used in quantum technology, bio \& medical instruments, laser displays, lighting and materials processing. The development of blue and green LDs is still challenging, even though they are based on the same III-nitride materials as GaN-based lightemitting diodes. The challenges and progress of GaN-based blue and green LDs are reviewed from the aspects of epitaxial growth and layer structure design. Due to large differences in lattice constants and growth conditions for $\mathrm{InN}, \mathrm{GaN}$, and AlN, considerable effort is required to improve the quality of InGaN multiple quantum well (MQW) gain medium for blue and especially green LDs. p-type doping profiles, conditions and layer structures are critical to reduce the internal losses and to mitigate the degradation of InGaN MQWs. Hole injection is also a key issue for GaN-based LDs.
\end{abstract}

Keywords: GaN-based LDs, InGaN, thermal degradation, In segregation, optical loss, carrier injection

\section{INTRODUCTION}

The invention and development of GaN-based lightemitting diodes (LEDs) have extended the wavelengths of semiconductor optoelectronic devices into the visible and ultraviolet spectrum ranges. GaN-based blue LEDs have been widely used in lighting and displays, and the Nobel Prize in Physics of 2014 honored the inventors of efficient blue LEDs-Professors Akasaki I, Amano H and Nakamura S [1-5]. GaN-based laser diodes (LDs), however, are different kinds of light sources with high brightness (4 orders of magnitude brighter than that of LEDs) and high spectral purity. Semiconductor LDs are now the most widely used lasers because of low costs, small sizes, high efficiencies and long lifetimes. Like the LEDs, GaNbased LDs have extended the visible and ultraviolet spectrum ranges. GaN-based violet LD with wavelength of $405 \mathrm{~nm}$ for the application of high-density optical storage was the first research focus of GaN-based LDs. GaN-based blue and green LDs have been studied intensely due to great potential for wide applications in displays, lighting, quantum technology, optical clock, medical instruments, materials processing and underwater communications and detection (Fig. 1a).

Laser displays using red, green and blue LDs are emerging technologies with larger color gamuts, higher color saturation, and capabilities for both pico-projectors and larger displays [6-11]. Fig. 1b compares the color gamuts of laser displays vs. other technologies [11]. GaNbased direct blue and green emission semiconductor LDs are thus desirable for laser displays. However, their fabrication is more challenging, compared with that of LEDs $[12,13]$.

There are four main difficulties to fabricate high-performance GaN-based blue and green LDs. First, as shown in Fig. 2, the LD epitaxial structures are more complex and more strained to form the optical cavity, which increases the complexity of epitaxial growth and causes more crystalline defects. Second, LDs are more sensitive to defects, including non-radiative recombination centers and inhomogeneity, both of which reduce the peak gain of LDs. Meanwhile, InGaN-based LEDs are not sensitive to defects because of the localization effect. Spectral broadening due to indium (In) composition fluctuations and interface roughness is a particular issue for green LDs whose gain medium is high-In-content InGaN multiple

\footnotetext{
${ }^{1}$ Key Lab of Nanodevices and Applications, Suzhou Institute of Nano-Tech and Nano-Bionics, Chinese Academy of Sciences, Suzhou 215123, China

${ }^{2}$ School of Nano-Tech and Nano-Bionics, University of Science and Technology of China, Hefei 230026, China

$\uparrow$ These two authors contributed equally to this work.

* Corresponding author (email: jpliu2010@sinano.ac.cn)
} 

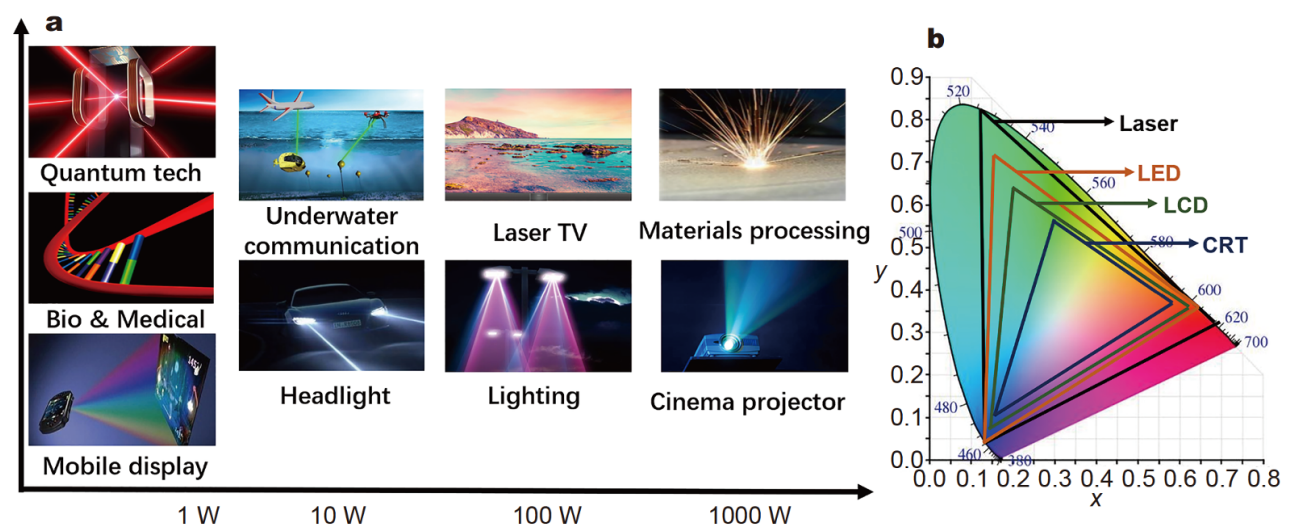

Figure 1 (a) Applications of GaN-based blue and green LDs. (b) Color gamut in the Commission Internationale de 1'Eclairage (CIE) chromaticity diagram of laser, LED, liquid crystal display (LCD) and cathode ray tube (CRT) display [11].

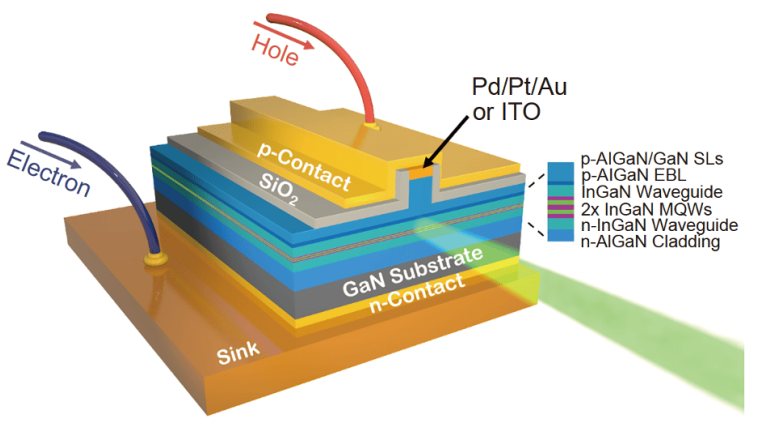

Figure 2 Schematic of a conventional GaN-based LD with a palladium $(\mathrm{Pd}) /$ platinum $(\mathrm{Pt}) /$ gold $(\mathrm{Au})$ electrode or a hybrid GaN-based LD with indium tin oxide (ITO) cladding layer. Reprinted with permission from Ref. [29]. Copyright 2020, Chinese Laser Press.

quantum wells (MQWs) [14]. Third, LDs are more sensitive to impurities because light will be strongly absorbed when propagating forward and backward many times within the cavity. Fourth, hole injection is usually inhomogeneous among MQWs because of the large effective masses of holes and the large potential barrier. Lack of holes in n-side quantum wells (QWs) will lead to high light absorption and, therefore, high threshold currents and reduced slope efficiencies for the LDs. In LEDs, either holes are injected into bottom QWs via V-pit sidewalls, or without hole injection, and light emission in the bottom QWs is not an issue.

The first GaN-based blue LDs were invented in 1999 by Nichia [15], while the first high-brightness LEDs was reported in 1993. The performance was improved in 2001 by using a free-standing GaN substrate [16]. The output power of GaN-based blue LDs was improved to $200 \mathrm{~mW}$ in 2005 [17], $500 \mathrm{~mW}$ in 2006 [18], $1 \mathrm{~W}$ in 2008 [19], and $5.25 \mathrm{~W}$ most recently [20]. However, the epitaxial growth and layer structures of GaN-based LDs have not been reported in significant detail. We have also obtained blue LDs with output powers more than $2 \mathrm{~W}$ [21], and recently have improved slope efficiencies to $1.65 \mathrm{~W} \mathrm{~A}^{-1}$ $[21,22]$. The development of GaN-based green LDs $(\lambda$ $>500 \mathrm{~nm}$ ) has been even more challenging. They were reported in 2009 by Osram Corp. [6]. Since then, green InGaN LDs grown on $c$-plane [6,23-29], (1122) plane [30], and (2021) plane [31-34] have been realized. Challenges and recent progresses on GaN-based blue and green LDs will be discussed below.

\section{CHALLENGES}

\section{Crystalline defects}

The first challenge is the preparation of high-quality InGaN/GaN MQWs, which is the gain medium of LDs, especially for high-In-content InGaN/GaN MQW green LDs. The quantum efficiency of GaN-based LEDs drops significantly as emission wavelength extends into the "green gap" [35,36], as shown in Fig. 3a. The efficiency of GaN-based LDs drops even more severely due to more complex structures. Table 1 lists the properties and general growth conditions of $\mathrm{GaN}$, AlN and InN [37]. The very different lattice constants and bond strengths result in large strains in the LD structures, and very different growth conditions are needed for different layers. Approximately $30 \%$ In must be incorporated in InGaN QWs to realize green LDs, which results in crystalline defects in three ways. First, because of weak In-N bonds, the growth temperature for InGaN must be lowered to incorporate sufficient In. Consequently, both the atomic diffusion length and the $\mathrm{NH}_{3}$ decomposition efficiency decrease at low temperatures, which results in crystalline 

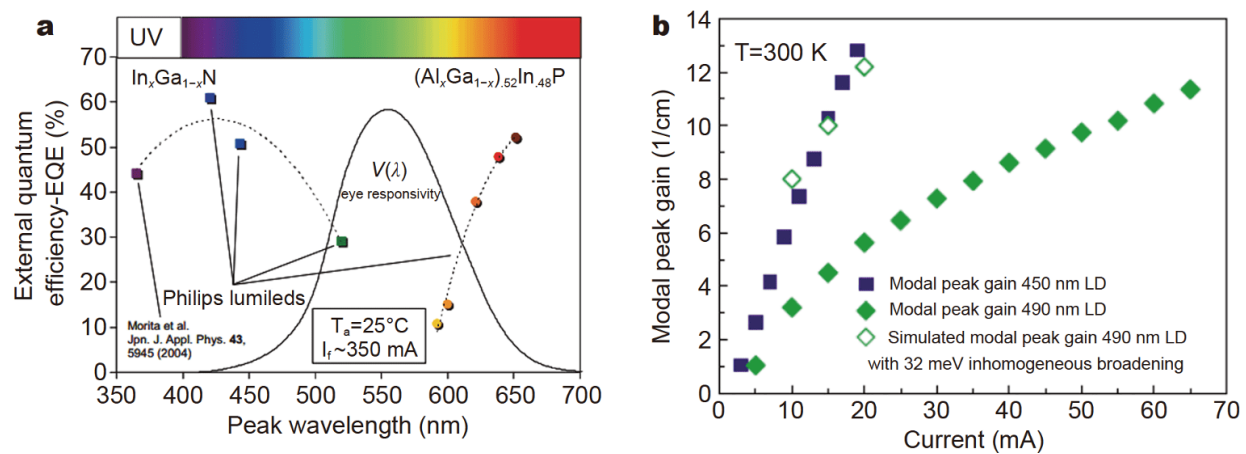

Figure 3 (a) External quantum efficiency $v s$. peak wavelength for high power LEDs based on III-nitride and III-phosphide systems. Reprinted with permission from Ref. [36]. Copyright 2008, John Wiley \& Sons. (b) Comparison of measured modal peak gain $v s$. current for 450 and $490 \mathrm{~nm}$ LDs. Reprinted with permission from Ref. [39]. Copyright 2011, AIP Publishing LLC.

defects, fluctuations of In composition, and rough interfaces in InGaN QWs because the growth temperature must be high enough to maintain a step-flow growth which is essential for a high-quality epitaxial growth [38]. Inhomogeneous broadening caused by In composition fluctuations and rough interfaces in InGaN QWs significantly lower the modal peak gain of green LDs [39], as shown in Fig. 3b. Secondly, the ideal growth temperature for a p-AlGaN cladding layer is as high as $1000^{\circ} \mathrm{C}$ to ensure low resistance. However, such high temperature will induce serious thermal degradation for both blue and green InGaN QWs [16,40-44]. Thirdly, the lattice mismatch between InGaN QWs and GaN is as large as 1.6\% for blue QWs and 3.3\% for green QWs, which induces crystalline defects in InGaN QWs. Crystalline defects not only reduce the radiative efficiency [45], but also shorten the device lifetimes [46].

\section{Light absorption}

The ionization energy of a magnesium $(\mathrm{Mg})$ dopant in $\mathrm{p}$ $\mathrm{GaN}$ is as large as $160 \mathrm{meV}$, and increases with aluminum (Al)-content in p-AlGaN $[47,48]$, making it the best dopant for p-(Al) GaN. Therefore, only less than $10 \%$ of $\mathrm{Mg}$ atoms are ionized and become free holes, and more than $90 \%$ form acceptor-bound holes, which are the main origin of light absorption in GaN-based LDs and create large internal optical losses [49-52]. Large internal optical losses lead to high threshold currents and low slope efficiencies [21,49].

\section{Carrier injection}

Hole injection is usually inhomogeneous among MQWs because of the large effective masses $\left(m_{0}\right)$ of holes and potential barrier, as reported extensively [53-55]. The effective masses of heavy holes in $\mathrm{GaN}$ and $\mathrm{InN}$ approach
Table 1 Properties and general growth conditions of GaN, AlN and InN [37]

\begin{tabular}{cccc}
\hline Sample & InN & GaN & AlN \\
\hline Lattice mismatch $(\%)$ & 11 & 0 & -2.4 \\
Bond strength $(\mathrm{eV})$ & 1.93 & 2.20 & 2.88 \\
V/III ratio & 30,000 & 2000 & 200 \\
Growth temperature $\left({ }^{\circ} \mathrm{C}\right)$ & $500-600$ & $1000-1100$ & $1350-1450$ \\
\hline
\end{tabular}

1.96 and $1.67 m_{0}$, respectively [56]. Moreover, the tilt of the potential barrier caused by the polarization field increases the hole transport barrier and makes n-side hole injection into the QWs difficult [57]. The lack of holes in the $\mathrm{n}$-side QWs results in high light absorption, and therefore high threshold current and reduced slope efficiency for LDs $[58,59]$.

\section{Quantum confined Stark effect}

GaN-based materials with $c$-plane orientations are the most mature for epitaxial growth. However, the quantum confined Stark effect (QCSE) is a challenge for fabricating $c$-plane green LDs. There are many detailed reports [6065] about QCSE, which originates from the polarization electric fields caused by both spontaneous and piezoelectric polarization charges at the heterointerface $[66,67]$. The polarization electric field has been estimated to be more than $2 \mathrm{MV} \mathrm{cm}^{-1}$ in green InGaN QWs $[68,69]$. Consequently, the overlap of electron-hole (e-h) wavefunctions is greatly reduced, as shown in Fig. 4, which results in low luminescence efficiency.

Because $c$-plane InGaN QWs suffer from the QCSE, nonpolar (a-plane, $m$-plane) InGaN QWs free from QCSE, and semipolar ( $r$-plane) InGaN QWs with small QCSE, have advantages for fabricating high performance green LDs [70]. Some groups (Sony \& Sumitomo [34,71], 


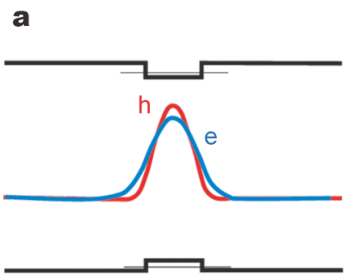

InGaN/GaN QW

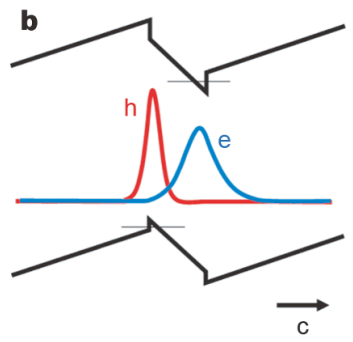

Figure 4 Schematic band diagram, and electron and hole wavefunctions without (a) and with (b) QCSE.

University of California at Santa Barbara (UCSB) [72,73]) have demonstrated green LDs based on these planes. However, crystalline defects such as stacking faults [74] and misfit dislocations readily appear in nonpolar and semipolar InGaN QWs, which limit the utilization of those planes.

\section{PROGRESS OF BLUE LDs}

\section{Epitaxial growth: suppression of dark spots}

Blue LD epitaxial structures were grown via a metalorganic chemical vapor deposition (MOCVD) on $c$-plane GaN substrates with a dislocation density of $10^{6} \mathrm{~cm}^{-2}$ or lower and then fabricated into ridge waveguide LD chips, schematically shown in Fig. 2. The epitaxial structure consisted of a silicon ( $\mathrm{Si}$ )-doped $\mathrm{n}-\mathrm{Al}_{0.08} \mathrm{Ga}_{0.92} \mathrm{~N}$ cladding layer, a Si-doped n-GaN layer, a Si-doped n- $\mathrm{In}_{0.04} \mathrm{Ga}_{0.96} \mathrm{~N}$ waveguide layer, two-period unintentionally-doped MQWs, an unintentionally-doped $\operatorname{In}_{0.02} \mathrm{Ga}_{0.98} \mathrm{~N}$ waveguide layer, a Mg-doped $\mathrm{p}-\mathrm{Al}_{0.2} \mathrm{Ga}_{0.8} \mathrm{~N}$ electron blocking layer, a $500 \mathrm{~nm} \mathrm{Mg-doped} \mathrm{p-AlGaN} \mathrm{cladding} \mathrm{layer} \mathrm{with}$ $7 \%$ average Al-content ( $\mathrm{p}-\mathrm{AlGaN} / \mathrm{p}-\mathrm{GaN}$ superlattice structures with periodic $2.5 \mathrm{~nm}$ p-AlGaN and $2.5 \mathrm{~nm} \mathrm{p}$ GaN to reduce resistivity), a p-InGaN contact layer, and a $\mathrm{Pd} / \mathrm{Pt} / \mathrm{Au}$ metal p-electrode.
The growth temperature for blue InGaN QWs is around $700^{\circ} \mathrm{C}$, while it is $950-1000^{\circ} \mathrm{C}$ for a $\mathrm{p}$-AlGaN cladding layer. During the high-temperature epitaxial growth of the $500 \mathrm{~nm}$ p-AlGaN cladding layer, a large thermal budget was imposed on the InGaN QWs, which thermally decompose. A Nikon A1 inverted laser confocal microscope with a $405 \mathrm{~nm}$ LD excitation laser source was used to image the luminescence of the blue QW active region of $\mathrm{LD}$ structures. Thermal decomposition of InGaN QWs leads to the formation of non-radiative recombination centers, which appear as dark spots in the image [16]. Fig. 5a-c show the fluorescence images of blue LD wafers with $\mathrm{p}$-AlGaN cladding layers grown at temperatures of 960,950 and $940^{\circ} \mathrm{C}$, respectively. The density of dark spots significantly decreased with the growth temperature of the $\mathrm{p}$-AlGaN cladding layer. The dark spots disappeared at $940^{\circ} \mathrm{C}$, indicating that reducing the p-AlGaN growth temperature suppressed thermal degradation of the QWs. This phenomenon occurs in epitaxial green LDs, except that the p-AlGaN growth temperature must be lowered further to suppress thermal degradation of green QWs $[22,43,44]$.

\section{Internal optical loss}

Reducing internal loss is also critical for LDs to reduce threshold currents and increase slope efficiencies [21]. Mg-doped layers are the dominant absorption origin in GaN-based LDs because high Mg doping concentrations in the level of $10^{19} \mathrm{~cm}^{-3}$ are usually used in p-type layers due to the low ionization ratio of $\mathrm{Mg}$ acceptors. The absorption is primarily from acceptor-bound hole absorption [51,52]. Blue LD structures have been numerically designed and experimentally optimized to reduce internal losses by reducing the overlap between the optical field and p-doped layers [75]. By increasing the thickness of an un-doped upper InGaN waveguide layer from 20 to $110 \mathrm{~nm}$, the internal loss was reduced from 60

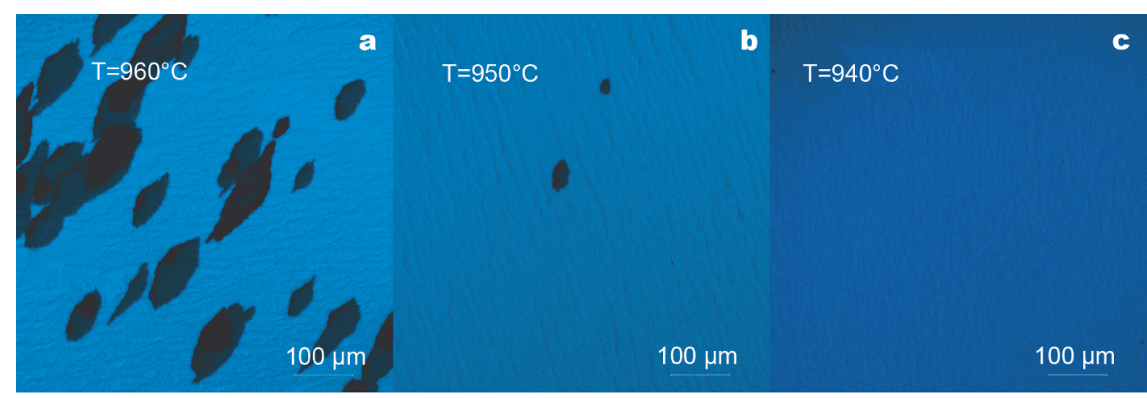

Figure 5 Fluorescence images of blue LD wafers with p-AlGaN cladding layers grown at temperatures of (a) $960^{\circ} \mathrm{C}$, (b) $950^{\circ} \mathrm{C}$ and $(c) 940^{\circ} \mathrm{C}$, respectively. Reprinted with permission from Ref. [22]. Copyright 2020, Chinese Laser Press. 

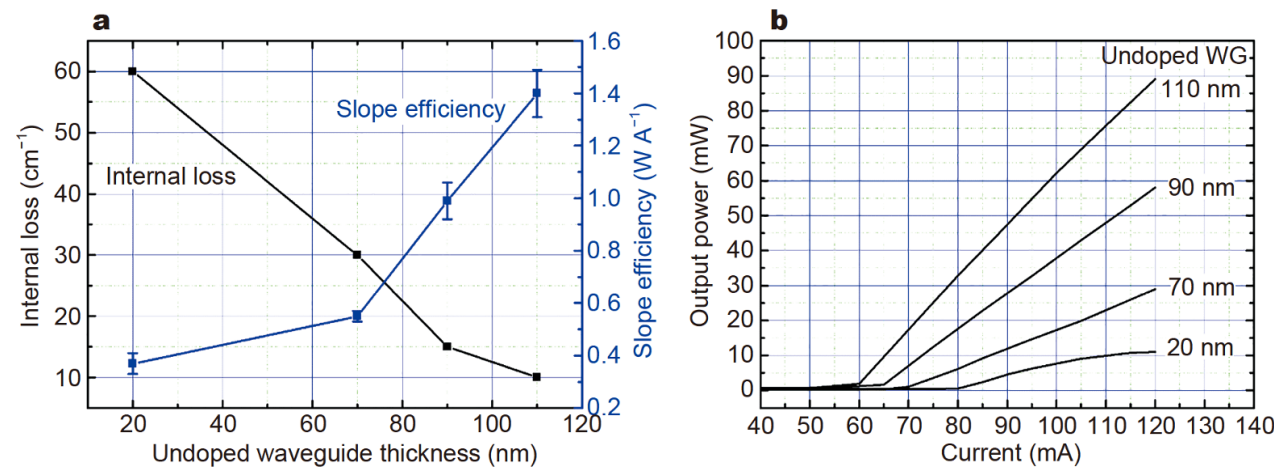

Figure 6 (a) Slope efficiencies and internal losses of LD chips dependent on the thickness of un-doped upper InGaN waveguide layer in the LD structures. (b) Typical $P$-I curves for LD chips with various thickness of un-doped upper InGaN waveguide layer. Reprinted with permission from Ref. [21]. Copyright 2017, IEEE.

to $10 \mathrm{~cm}^{-1}$, as measured by the Hakki-Paoli method. Fig. 6a shows that the slope efficiencies and the internal losses of LD chips depend on the thicknesses of un-doped upper InGaN waveguide layer in the LD structures. Fig. $6 \mathrm{~b}$ shows typical power-current $(P-I)$ curves for LD chips with various thickness of un-doped upper InGaN waveguide layer. The slope efficiency was $0.36,0.58,1.1$, and $1.5 \mathrm{~W} \mathrm{~A}^{-1}$ for LD chips with $20,70,90$, and $110 \mathrm{~nm}$ thick un-doped upper waveguides, respectively. The LD chips had ridge waveguide structures with ridge length of $0.4 \mathrm{~mm}$, and their coating reflectivities of rear and front facets were $95 \%$ and $34 \%$, respectively. The slope efficiency was measured under continuous-wave (CW) operation at room temperature. Eight LD chips were measured to obtain slope efficiency data for each LD layer structure as shown in Fig. 6a. The data points were the averaged values, and the small variations were also plotted in Fig. 6a.

\section{Hole transport and distribution}

Holes in GaN-based materials have a large effective mass and a low mobility, making it difficult to electrically inject them into n-side QWs [22,53-55]. The QWs of LDs require uniform carrier injection to achieve population inversion to form optical gain. Therefore, it is important to optimize the structure of the QWs to improve the carrier distribution for the MQW of LDs. Our previous research found that under electrical injection, holes were only distributed in the QW close to $\mathrm{p}-\mathrm{GaN}$ when the quantum barrier $(\mathrm{QB})$ thickness of the blue LED was $13 \mathrm{~nm}$. Reducing the thickness and/or the height of the QB can improve hole injection to $\mathrm{n}$-side QWs [58,59]. We fabricated two blue LDs with different barrier thicknesses. The P-I curves are shown in Fig. 7. The threshold

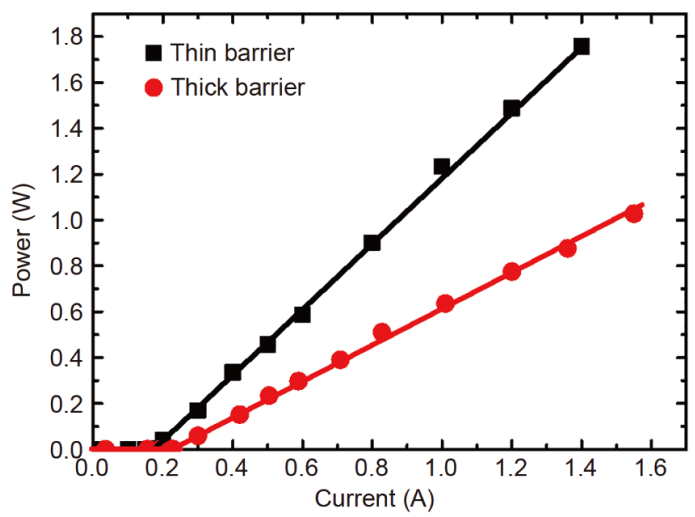

Figure 7 P-I curves of blue LDs with different barrier thickness. Reprinted with permission from Ref. [22]. Copyright 2020, Chinese Laser Press.

current density of the thin barrier LD was $1 \mathrm{kA} \mathrm{cm}^{-2}$ and the slope efficiency was $1.5 \mathrm{~W} \mathrm{~A}^{-1}$. The threshold current density of the thick barrier LD was $1.4 \mathrm{kA} \mathrm{cm}^{-2}$ and the slope efficiency was only $0.8 \mathrm{~W} \mathrm{~A}^{-1}$. This was caused by a more uniform hole distribution in the QWs and a higher carrier injection efficiency for the thin barrier blue LD. Thus, the slope efficiency was higher than that of the thick barrier LD.

\section{Determination of internal parameters}

To obtain internal parameters such as internal optical loss $\left(\alpha_{\mathrm{i}}\right)$ and carrier injection efficiency $\left(\eta_{\text {inj }}\right)$ of our blue LDs, three blue LDs were fabricated with different front-facetcoating reflectivities [22]. The $P-I$ curves are shown in Fig. 8a. The threshold current density of the LD with the front-facet-coating reflectivity of $10 \%$ was $2.4 \mathrm{kA} \mathrm{cm}^{-2}$ and the slope efficiency was $1.6 \mathrm{~W} \mathrm{~A}^{-1}$, while the 

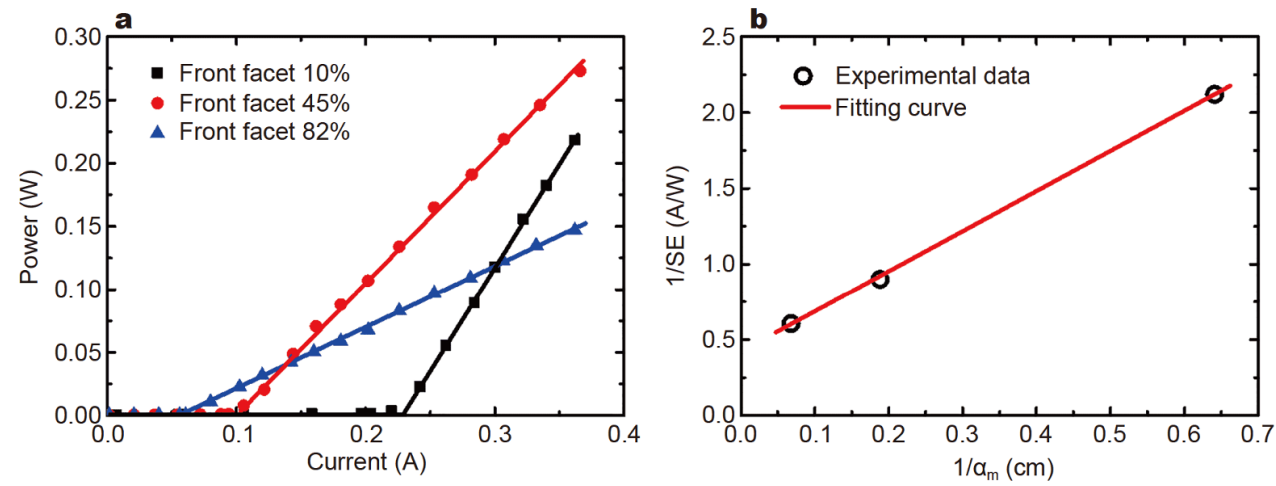

Figure 8 (a) Three $P$ - $I$ curves of blue LDs with different front-facet-coating reflectivities, and (b) the inverse of SE as a function of the inverse of $\alpha_{\mathrm{m}}$ for these three blue LDs, and the red line is a linear fitting. Reprinted with permission from Ref. [22]. Copyright 2020, Chinese Laser Press.

threshold current densities of the LDs with reflectivities of $45 \%$ and $82 \%$ were 1 and $0.6 \mathrm{kA} \mathrm{cm}^{-2}$, respectively. The slope efficiencies were 1.1 and $0.5 \mathrm{~W} \mathrm{~A}^{-1}$, respectively. LD mirror loss $\left(\alpha_{\mathrm{m}}\right)$ is determined by the front- and rearfacet-coating reflectivities and the cavity length [76]. The relationship of $\alpha_{\mathrm{i}}, \alpha_{\mathrm{m}}, \eta_{\mathrm{ini}}$, and slope efficiency (SE) of an LD can be described by $[77,78]$ :

$\frac{1}{\mathrm{SE}}=\frac{q \lambda}{h c \eta_{\mathrm{inj}}}\left(1+\alpha_{\mathrm{i}} \frac{1}{\alpha_{\mathrm{m}}}\right)$.

Fig. $8 \mathrm{~b}$ plots the inverse of SE as a function of the inverse of $\alpha_{\mathrm{m}}$ for these three blue LDs, and the red line is a linear fitting. According to the formula mentioned above, the $\eta_{\text {inj }}$ can be obtained from the intercept of the fitting curve, and the $\alpha_{\mathrm{i}}$ can be obtained by the slope of the fitting curve, since electronic charge $(q)$, wavelength $(\lambda)$, Planck constant $(h)$, and light speed $(c)$ are known constants. By doing so, the $\alpha_{\mathrm{i}}$ and the $\eta_{\text {inj }}$ of the blue LDs were determined to be $6.8 \mathrm{~cm}^{-1}$ and $90 \%$, respectively. For blue LDs, Becerra et al. [79] reported an $\alpha_{\mathrm{i}}$ of $9 \mathrm{~cm}^{-1}$ and an $\eta_{\text {inj }}$ of 73\%, and Ryu et al. [80] reported an $\alpha_{\mathrm{i}}$ of $9 \mathrm{~cm}^{-1}$ and an $\eta_{\text {inj }}$ of $89 \%$. Kawaguchi et al. [81] reported an $\alpha_{\mathrm{i}}$ of $7 \mathrm{~cm}^{-1}$ and an $\eta_{\text {inj }}$ of $96 \%$ for violet LDs with the undoped upper waveguide thickness of $100 \mathrm{~nm}$. By increasing the undoped waveguide thickness to $1100 \mathrm{~nm}$, they reduced the $\alpha_{\mathrm{i}}$ to $2 \mathrm{~cm}^{-1}$ but at the expense of a decreased $\eta_{\text {inj }}$ of $85 \%$.

\section{LD characteristics}

Blue LDs were also fabricated and packaged with ridge size of $45 \mu \mathrm{m}$ wide and $1200 \mu \mathrm{m}$ long [22]. The LD characteristics were measured under pulse operation at room temperature. The pulse width was $0.4 \mu$ s and the repetition rate was $10 \mathrm{kHz}$ to minimize self-heating effects. The red data points in Fig. 9a were the optical powers at different currents (up to $1.7 \mathrm{~A}$ because of the limitation of pulsed current source). The threshold current density of the laser was $1 \mathrm{kA} \mathrm{cm}^{-2}$, and the slope efficiency was $1.65 \mathrm{~W} \mathrm{~A}^{-1}$. The red line was used to extrapolate the optical power to $3 \mathrm{~A}$ (current density of
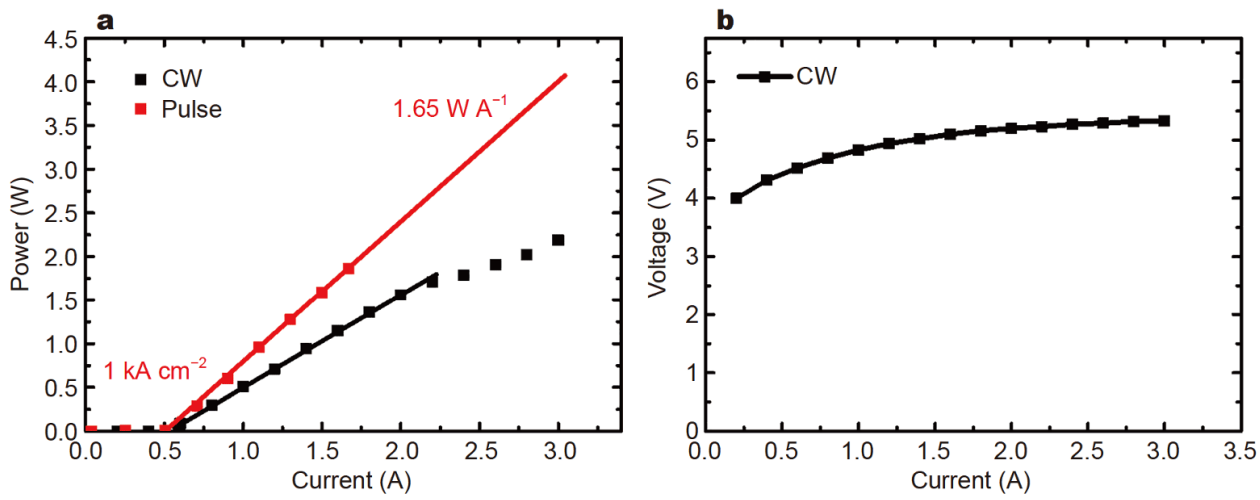

Figure 9 (a) $P$ - I curves of a blue LD with a $45 \mu \mathrm{m}$ ridge width and a $1200 \mu \mathrm{m}$ cavity length under pulse (red) and CW (black) operation. (b) $I$ - $V$ curve of the blue LD under CW operation. Reprinted with permission from Ref. [22]. Copyright 2020, Chinese Laser Press. 
$6 \mathrm{kA} \mathrm{cm}^{-2}$ ), which was expected to reach $4 \mathrm{~W}$. The black data points were output powers under CW operation, where the threshold current was the same, but the slope efficiency significantly decreased to $1 \mathrm{~W} \mathrm{~A}^{-1}$. At a current density of $6 \mathrm{kA} \mathrm{cm}^{-2}$, the output power was $2.2 \mathrm{~W}$. The decrease of slope efficiency was caused by poor heat dissipation of the package. The current-voltage $(I-V)$ curve is shown in Fig. 9b, where the operating voltage was $5.3 \mathrm{~V}$ at a current density of $6 \mathrm{kA} \mathrm{cm}^{-2}$. The internal parameters including optical loss and injection efficiency, and the LD characteristics including threshold current density and slope efficiency, indicated our blue LDs were comparable to the state-of-the-art.

\section{PROGRESS OF GREEN LDS}

Fabrication of green LDs is more challenging than that of blue LDs, because more In must be incorporated to extend the emission wavelength to the green range. In addition, the InGaN/GaN MQW active region of green LDs suffers more severe thermal degradation [41,43], In segregation $[82,83]$, and lattice mismatch. Besides, a lower growth temperature of the $\mathrm{p}-\mathrm{AlGaN}$ cladding layer than that of blue LDs must be used to suppress the thermal degradation, which results in a relatively high series resistance of green LDs. Extensive efforts have been made to improve the luminescence homogeneity and the efficiency of green LD active region [26,27,84]. In order to suppress the thermal degradation, low temperature growth and $\mathrm{p}$-doping of the $\mathrm{p}$-AlGaN cladding layer were examined $[28,48]$. Besides, hybrid green LDs with an indium tin oxide (ITO) cladding layer have been fabricated to further suppress the thermal degradation of the green InGaN MQW active region. Hence, the performance of hybrid green LDs has been greatly improved [29].

\section{Improvement of luminescent homogeneity}

The epitaxial growth of the InGaN/GaN MQW active region with high internal quantum efficiency (IQE) and high differential gain is a key point to realize green LDs with low threshold current. Therefore, green InGaN/GaN MQWs with sharp interfaces and homogeneous luminescence are important to lower the threshold current of green LDs.

Step-flow growth of InGaN QWs can result in smooth morphologies and thus sharp QW interfaces. Oliver et al. $[85,86]$ intensively studied the growth modes of InGaN on $\mathrm{GaN}$, and reported step-flow growth for InGaN QWs with lower In-content than in green InGaN QWs. However, green InGaN QWs with high In-content, which must be grown at temperature lower than $700^{\circ} \mathrm{C}$, usually exhibit two-dimensional (2D) island morphology or 3D morphology [84,85-90]. Increasing defects, related to In segregation, at green InGaN/GaN QW interfaces, could be another reason for the rough interface and low IQEs. [84,91-93]. Therefore, to increase the IQE and improve the luminescence homogeneity, the ways to realize stepflow growth of green InGaN QWs were studied to suppress the formation of interfacial defects for green InGaN/GaN MQWs.

As shown in Fig. 10a, adatoms either diffuse on the epitaxial growth surface and incorporate into atomic steps, or aggregate and nucleate two-dimensionally depending on the substrate terrace width and adatom diffusion length. Step-flow growth is desirable to obtain high-quality QWs with high emission efficiencies and homogeneity. The growth temperature must be lowered to increase the In-content to around 30\% in InGaN QWs for green emission. Reduced adatom diffusion lengths at lower temperatures resulted in 2D growth and morphologies. Substrates with large miscut angles and thus narrower atomic terraces were used to grow InGaN QWs with high In-content. As shown in Fig. 10b, we established a relationship between the growth mode and substrate miscut angle, i.e., atomic terrace width. For a higher In-content of InGaN QW, a larger substrate miscut angle was needed to obtain step flow growth. Fig. 10c and $\mathrm{d}$ show the atomic force microscopy (AFM) images of 2D island morphology and step-flow morphology, respectively. The root-mean-square (RMS) roughnesses for $1 \times 1 \mu \mathrm{m}^{2}$ scan areas were 0.24 and $0.16 \mathrm{~nm}$, respectively. Although the roughness was similar, their origins were different. The former resulted more from the $2 \mathrm{D}$ morphology, while the latter resulted more from the atomic step edges because it had a greater two-fold step density. Surface height fluctuation for the 2D islands ranged from 0.6 to $1.2 \mathrm{~nm}$, while the step height was $0.26 \mathrm{~nm}$ for the step-flow morphology. Thus, In atoms tended to segregate at the edges of $2 \mathrm{D}$ islands where strain relaxation was allowed. Improved luminescent homogeneity was therefore expected for step-flow growth. Temperature dependent photoluminescence (PL) results of the green InGaN/ GaN MQWs grown on GaN substrates with the step-flow morphologies had an IQE one-fold higher than that of MQWs with 2D island morphologies. Moreover, the room-temperature emission line-width of green InGaN/ GaN MQWs was greatly reduced from $166 \mathrm{meV}$ for 2D island morphologies to $131 \mathrm{meV}$ for step-flow morphologies at an emission wavelength of $536 \mathrm{~nm}$.

Green InGaN/GaN MQWs are highly strained and 

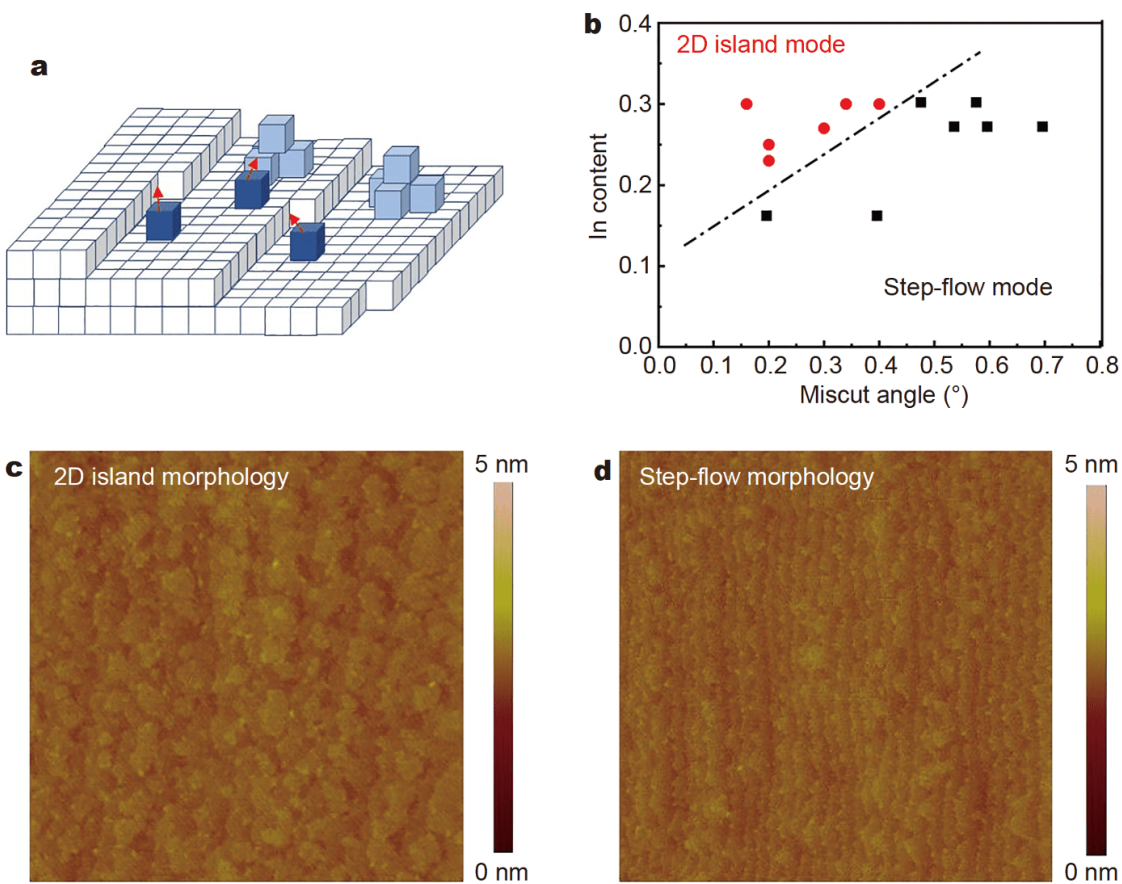

Figure 10 (a) Schematic of formation of different growth modes and morphologies. (b) Relationship between the growth mode of InGaN QWs and the substrate miscut angle depending on In-content; AFM images $\left(1 \times 1 \mu \mathrm{m}^{2}\right)$ of green InGaN QW samples grown on $c$-plane GaN substrates with miscut angles of (c) $0.20^{\circ}$, and (d) $0.48^{\circ}$. Reprinted with permission from Ref. [27]. Copyright 2017, AIP Publishing LLC.

must be grown at low temperatures with a large lattice mismatch. This causes a high density of trench defects at the interface, as shown in Fig. 11a. These defects greatly lower their emission efficiency of green InGaN/GaN MQWs [91-93], and are a challenge for green LDs with constant temperature growth (1T growth) of InGaN/GaN MQW active regions, i.e., the same growth temperature for InGaN QWs and GaN QBs, as schematically shown in Fig. 11b. The formation of trench defects is closely related to In segregation, and can be eliminated by the thermal annealing process in which, QWs are grown at $700^{\circ} \mathrm{C}$ and then the temperature is ramped to $850^{\circ} \mathrm{C}$ to desorb excess In at the growth surface. The QBs were grown at $850^{\circ} \mathrm{C}$ to avoid the formation of trench defects, i.e., two temperature growth (2T growth), as schematically shown in Fig. 11b. However, the thermal annealing process resulted in high density of voids $\left(2.8 \times 10^{8} \mathrm{~cm}^{-2}\right)$ at the surface of the QWs, producing a rough $\mathrm{QW} / \mathrm{QB}$ interface, as shown in Fig. 11c. Besides, thermal annealing process will result in In composition fluctuations caused by In desorption, both of which resulted in broadening of emission spectra. Therefore, an approach to suppress the formation of trench defects rather than thermal annealing process was examined to reduce the emission linewidth of the green InGaN/GaN MQW active region [94]. It was found that the density of trench defects in green InGaN/GaN MQWs could be suppressed by an order of magnitude by increasing the V/III ratio from 13,000 to 26,000 , as shown in Fig.11a and d, and could be further reduced to $5 \times 10^{5} \mathrm{~cm}^{-2}$ by growth on a GaN substrate [94]. Hence, high quality green InGaN/GaN MQWs with $1 \mathrm{~T}$ growth were demonstrated, as shown in Fig. 11e. A scanning transmission electron microscopy (STEM) image in Fig. 11f of green InGaN/GaN MQWs with $1 \mathrm{~T}$ growth indicated a very sharp interface. The optical quality of green InGaN/GaN MQWs was thus greatly improved, as indicated by an increased PL intensity and nonradiative recombination lifetime and decreasing spectra full width at half maxima (FWHMs) [94]. Fig. 12 shows a comparison of spectral FWHMs $v s$. emission energy, reported by various research groups. It revealed that the FWHMs of $113 \mathrm{meV}$ at an emission wavelength of $530 \mathrm{~nm}$ for our green InGaN/GaN MQWs was the best reported value so far.

\section{Suppression of thermal degradation}

During subsequent p-type AlGaN cladding layer growth, InGaN MQWs tend to degrade in crystalline quality and emission efficiency, and even decompose due to instability at temperatures for p-AlGaN growth [40-44]. 

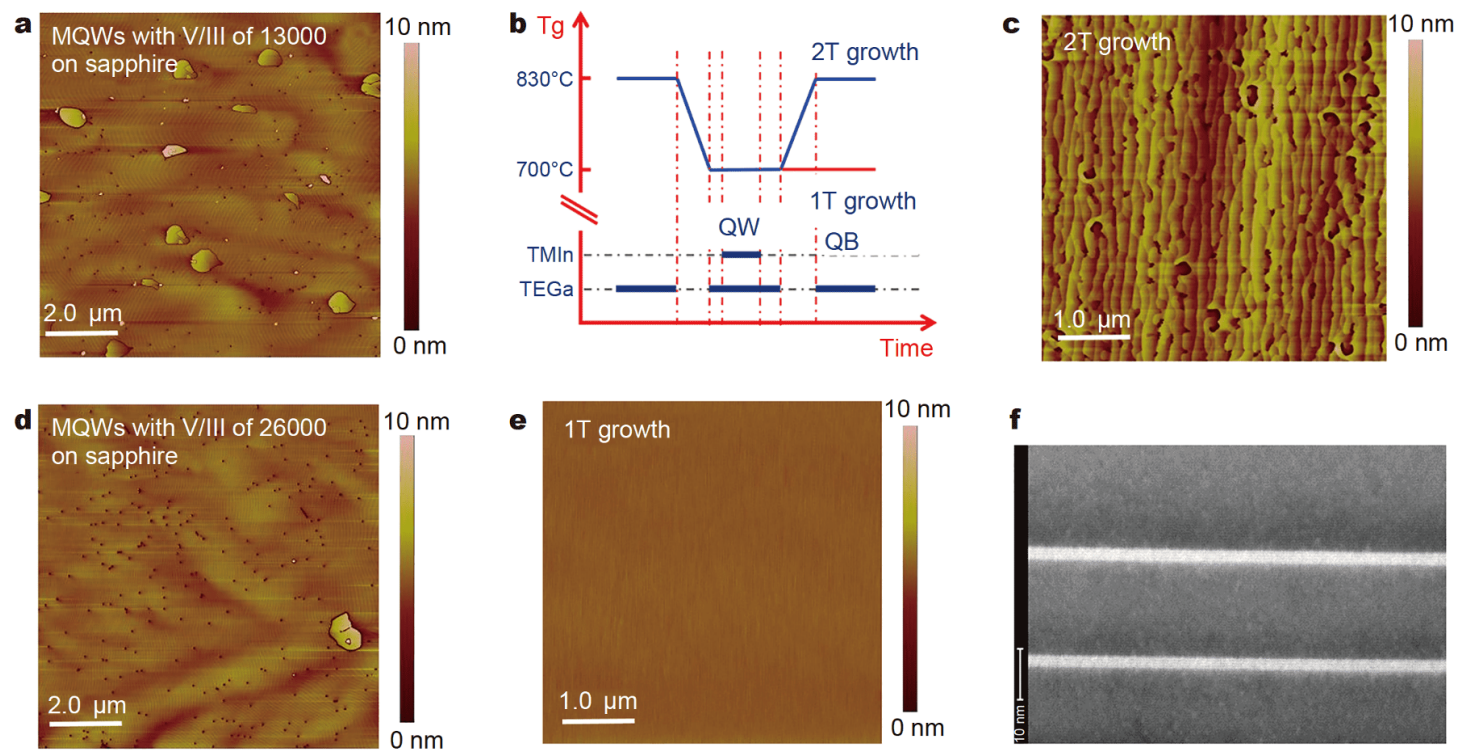

Figure 11 (a) AFM image of green InGaN/GaN MQWs with V/III ratio of 13,000. (b) Schematic of 1T growth and 2T growth. (c) AFM image of green InGaN/GaN MQWs from 2T growth. Reprinted with permission from Ref. [84]. Copyright 2017, The Optical Society. (d) AFM image of green InGaN/GaN MQWs with V/III ratio of 26,000. Reprinted with permission from Ref. [94]. Copyright 2019, The Japan Society of Applied Physics. (e) AFM and (f) STEM images of green InGaN/GaN MQWs from 1 T growth.

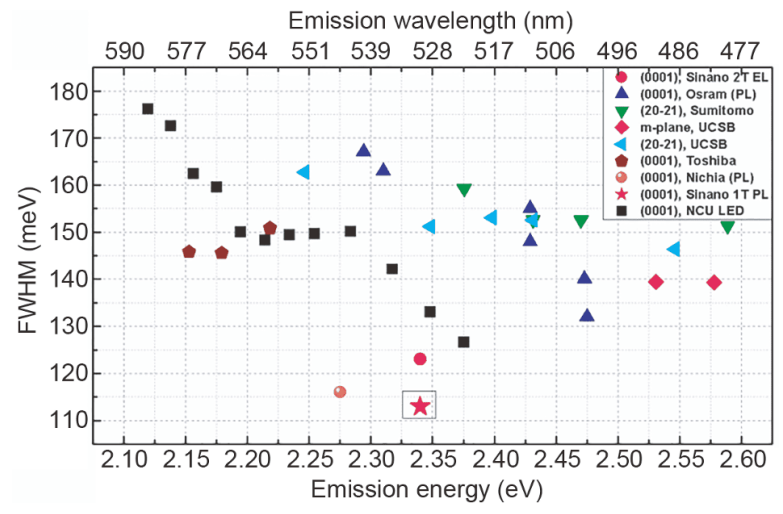

Figure 12 Spectral FWHMs $v s$. emission energy for green and yellow GaN-based LEDs. The red solid circle is our electroluminescence (EL) FWHMs of $2 \mathrm{~T}$ grown green LD [84], the red solid star is our PL FWHMs of $1 \mathrm{~T}$ grown green MQWs [94], the black solid squares are LEDs grown on Si substrates from Nanchang University [95], and other data are PL for LD structures grown on GaN from Nichia [96], EL for LEDs grown on sapphire from Toshiba [97], PL for an LD structure grown on GaN from Osram [42], EL for an LD structure grown on (2011) plane GaN substrate from Sumitomo [32], and EL for an LD structure grown on $(20 \overline{2} 1)$ plane GaN substrate from UCSB $[98,99]$.

Thermal degradation is more severe in green LD structures with high In-content in the InGaN/GaN MQW active region. As shown in Fig. 13a, there was a high density of dark regions with different grey scales in micro-PL images of LD wafer, which indicated no or weak
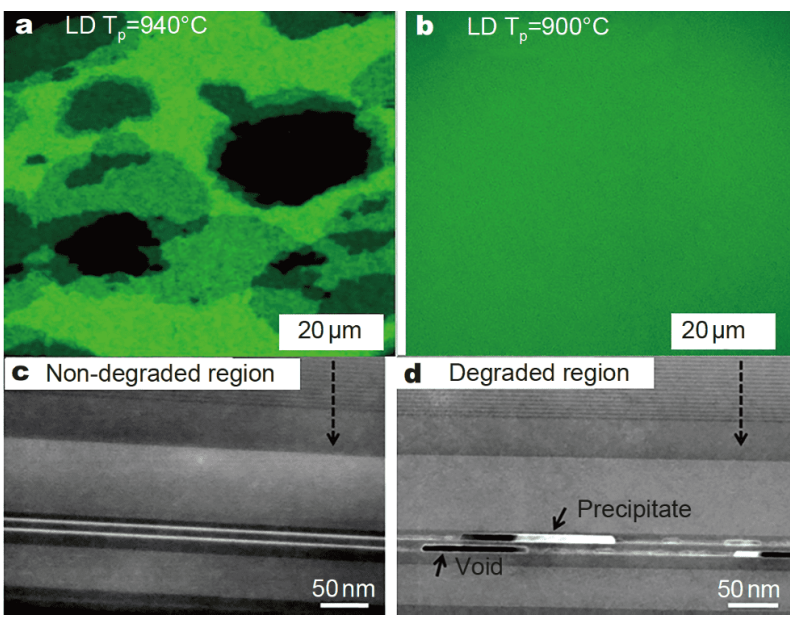

Figure 13 Micro-PL images of a green LD structure with p-AlGaN grown at (a) $940^{\circ} \mathrm{C}$ and (b) $900^{\circ} \mathrm{C}$. STEM images of (c) non-degraded and (d) degraded regions. Reprinted with permission from Ref. [43]. Copyright 2013, AIP Publishing LLC.

emission caused by the thermal degradation. The different grey scales may indicate that the decomposition occurred in the top or bottom QW simultaneously. To mitigate the thermal budget imposed on InGaN QWs, the growth temperature of p-type layers was lowered by $40^{\circ} \mathrm{C}$, and homogeneous luminescent image was obtained, as shown in Fig. 13b. It was noted that the degradation of 
InGaN QW was suppressed because of the reduced thermal budget during p-type growth. Fig. 13c shows STEM images of the non-degraded region, which featured continuous and homogeneous InGaN QWs. Bright precipitates and black voids were observed in STEM images of the degraded region, as shown in Fig. 13d. The degradation was caused by thermal decomposition of Inrich InGaN initiated at the In-rich InGaN clusters located at the surface of InGaN QW [43]. Metallic In clusters were generated as a result of the decomposition. By suppressing the thermal degradation, the emission efficiency of the green LD structure was greatly improved [43].

\section{Carbon impurities in the p-AlGaN:Mg cladding layer}

To suppress thermal degradation of green InGaN/GaN QWs with high-In-content during the growth of p-type AlGaN cladding layers [6,43], p-type cladding layers were usually grown at a temperature lower than optimal temperature which was higher than $1000^{\circ} \mathrm{C}$ for $\mathrm{AlGaN}$. However, p-type AlGaN growth at a low temperature often had high resistivity due to increased defects and impurity incorporations [100-103]. Because of the chemical activity of $\mathrm{Al}$, the $\mathrm{AlGaN}$ layer grown by MOCVD usually contained higher carbon impurity concentrations than GaN especially when the growth temperature was reduced below the optimal growth temperatures. The dependence of carbon concentration on growth conditions was examined [28,48]. As shown in Fig. 14a, when the p-type AlGaN cladding layer was grown at a lower temperature to avoid the thermal degradation of the active region, the incorporation of carbon impurities was enhanced. However, by adopting a lower growth rate and a higher growth pressure, carbon concentrations in $\mathrm{p}$ type AlGaN could be suppressed to less than $1 \times 10^{17} \mathrm{~cm}^{-3}$, as shown in Fig. 14b and c. A correlation between carbon concentration and electrical properties of $\mathrm{AlGaN}: \mathrm{Mg}$ was obtained. When the carbon concentration was higher than a certain level in the order of $10^{17}$, there was a clear tendency that the hole concentrations decreased and the resistivity increased with the carbon concentration, as shown in Fig. 14d. Based on the analysis of the charge neutrality equation, carbon impurities acted as the main compensating donors in AlGaN:Mg. The carbon impurity concentration also decreased as the substrate misorientation angle increased, which was attributed to reduced step motion velocity for epitaxial growth on substrates with larger misorientation angles [104].

Spontaneous recombination IQEs were estimated via temperature-dependent PL measurements to evaluate the
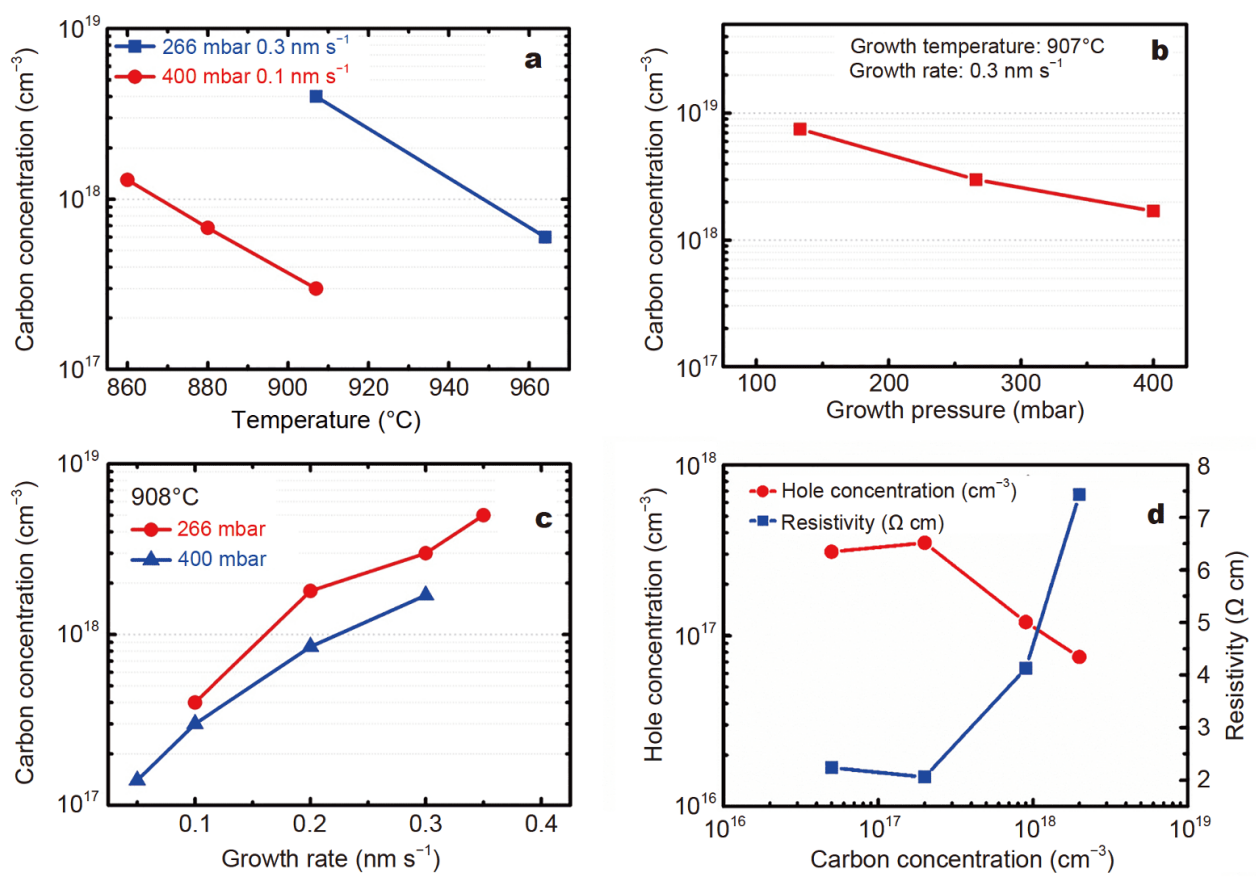

Figure 14 Dependence of growth conditions on carbon incorporation: (a) growth temperature, (b) growth pressure, and (c) growth rate. (d) Hole concentration and resistivity vs. carbon concentration. Reprinted with permission from Ref. [48]. Copyright 2015, The Japan Society of Applied Physics. 


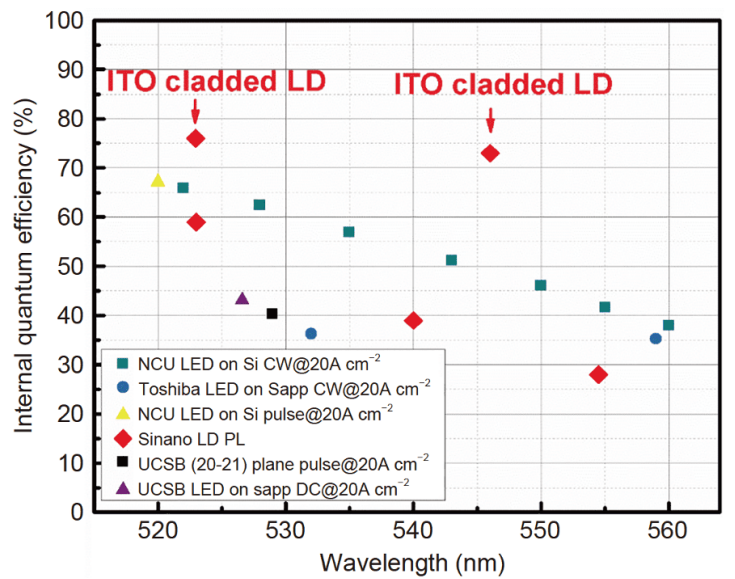

Figure 15 Spontaneous recombination IQE data for our green LD structures and LEDs. Data from Nanchang University were calculated using external quantum efficiency data assuming an extraction efficiency of $70 \%[95,109]$. The red rhombus points are data of our conventional green LDs [26] and hybrid LDs with ITO cladding layer. Other data are from Toshiba $[97,110]$ and UCSB [111,112]. Our data are measured via PL for LD structures grown on free-standing GaN substrates, while the literature data were measured via EL from LEDs grown on Si or sapphire substrates.

quality of MQW active regions in green LD structure. As shown in Fig. 15, the IQEs of conventional green LD structures with $500 \mathrm{~nm}$ p-AlGaN cladding layers were $59 \%, 39 \%$ and $29 \%$ for samples with emission wavelengths of 523, 540 and $554 \mathrm{~nm}$, respectively. Because there have been no reports of spontaneous recombination IQEs for LD structures, state-of-the-art results for LEDs are also shown in Fig. 15. It should be noted that our data were measured by PL for LD structures grown on freestanding GaN substates, while literature data were measured by EL for LEDs grown on Si or sapphire substrates. It can be seen that the IQEs of our conventional green LD structures with metal electrodes were a little lower than the best results reported by Nanchang University, but were comparable to other reports. Therefore, by improving the epitaxial growth of green InGaN QWs and adopting low temperature growth and p-doping of $\mathrm{p}$ AlGaN cladding layer under optimized conditions to suppress carbon impurities, spontaneous recombination IQE of our green LD structures was greatly enhanced. Fig. 16a and $\mathrm{b}$ show threshold current density and slope efficiency $v s$. lasing wavelength for green LDs reported in a review paper by Monavarian et al. [105]. The threshold current density and slope efficiency of our green LDs were comparable to the state-of-the-art results. Although the dislocation density of LD structures grown on sapphire substrates was two orders of magnitude higher than those grown on GaN substrates, high IQEs of $41.1 \%$ at wavelength of $527 \mathrm{~nm}$ and $24.3 \%$ at wavelength of $615 \mathrm{~nm}$ were also obtained by using quantum dots as gain medium [106,107]. This enabled low-threshold green vertical-cavity surface-emitting lasers (VCSEL) under electrical injection [108].

\section{Hybrid green LDs with ITO cladding layers}

ITO is conductive and transparent in the visible spectrum range and has been widely used as an electrode in GaNbased LEDs. Its absorption coefficient is two orders of magnitude lower than that of metals [113-115], and its refractive index is around 2 [116], which is much lower than that of the p-AlGaN cladding layer. It therefore provides sufficient optical confinement for the laser cavity. ITO can be deposited around $300^{\circ} \mathrm{C}$ or lower. Thus, replacing a $\mathrm{p}-\mathrm{AlGaN}$ cladding layer with ITO can reduce the high-temperature growth time of the p-AlGaN cladding layer, and thus reduce the thermal budget imposed on green InGaN QWs. Moreover, using ITO as the cladding layers also allows a lower Al-content $\mathrm{p}-\mathrm{AlGaN}$ cladding layer to be used in hybrid LD structures. This enhances the electrical properties of the cladding layer
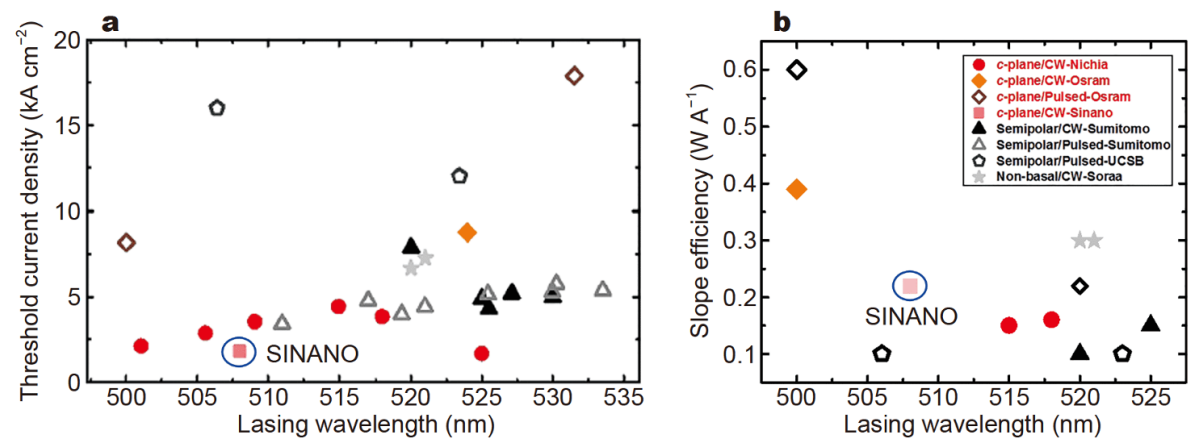

Figure 16 (a) Threshold current density $v$ s. lasing wavelength for green LDs, and (b) slope efficiency $v s$. lasing wavelength for green LDs. Reprinted with permission from Ref. [105]. Copyright 2018, John Wiley \& Sons. 

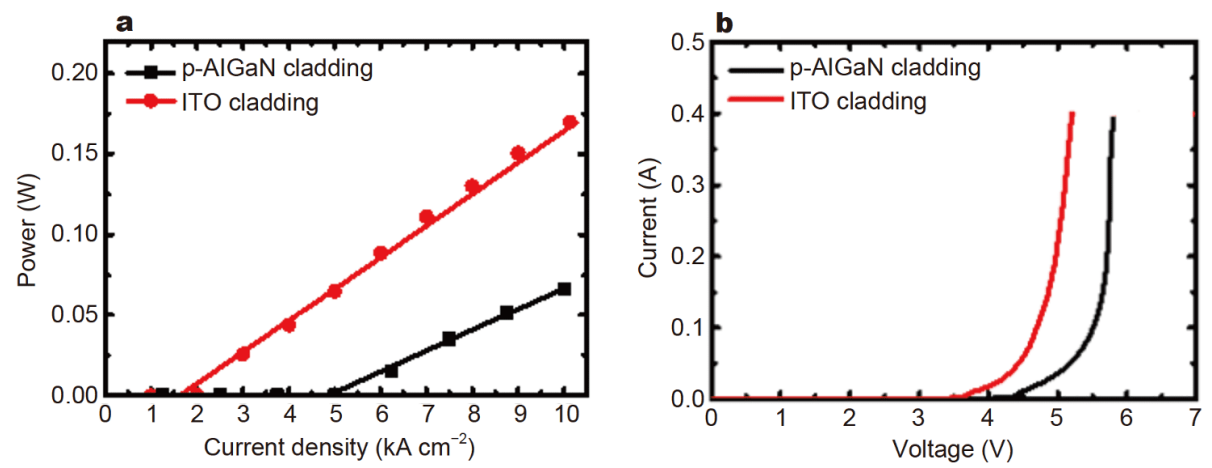

Figure 17 (a) $P-I$ curves of ITO LDs with $300 \mathrm{~nm} \mathrm{p}-\mathrm{Al}_{0.035} \mathrm{Ga}_{0.965} \mathrm{~N}$ cladding layer and conventional LDs, and (b) $I$ - $V$ curves of two different LDs.

including hole concentration and conductivity $[28,48]$. Therefore, the hybrid GaN-based LDs using ITO as pcladding layer is promising to improve the performance of GaN-based LDs. There have been a few reports about the design and fabrication of hybrid GaN-based LDs using ITO as a cladding layer. However, the performance is only comparable to LDs with conventional structures [117-120].

The hybrid green LDs with ITO cladding layers were designed and fabricated to suppress thermal degradation of green InGaN QWs. The performance of hybrid green LDs was greatly improved and the LD structure is shown in Fig. 2. A $200 \mathrm{~nm}$ ITO layer was used to replace part of the p-AlGaN cladding layer. ITO is also a p-electrode, replacing the normal $\mathrm{Pd} / \mathrm{Pt} / \mathrm{Au}$ metal.

The spontaneous recombination IQEs of green LD structures with ITO cladding layer was estimated via temperature-dependent PL measurements. The excitation light source was a $405 \mathrm{~nm}$ laser and the excitation power density was $2.4 \mathrm{~kW} \mathrm{~cm}{ }^{-2}$. The IQE is the ratio of the integrated intensity at room temperature to that at $10 \mathrm{~K}$, assuming that nonradiative recombination is frozen and thus IQE is $100 \%$ at $10 \mathrm{~K}$. As shown in Fig. 15, the IQE of hybrid green LD structure with a thinner p-AlGaN increased to $76 \%$ at wavelength of $523 \mathrm{~nm}$. Hence, reducing the p-AlGaN thickness and its growth time further suppressed the thermal degradation of green QWs [40-44].

Hybrid green LDs with ITO cladding layers were measured by probing LD bars under pulsed operation at room temperature. The P-I curves for ITO LDs and conventional LDs are shown in Fig. 17a. The threshold current density of a conventional LD was $5 \mathrm{kA} \mathrm{cm}^{-2}$, and the slope efficiency was $0.16 \mathrm{~W} \mathrm{~A}^{-1}$; whereas the threshold current density of ITO LDs with a $\mathrm{p}-\mathrm{Al}_{0.035} \mathrm{Ga}_{0.965} \mathrm{~N}$ cladding layer was $1.6 \mathrm{kA} \mathrm{cm}^{-2}$, and the slope efficiency was $0.2 \mathrm{~W} \mathrm{~A}^{-1}$. Our simulation indicated that the con- finement factors of these two samples were almost the same. The simulated total internal loss of the sample with $300 \mathrm{~nm}$ p- $\mathrm{Al}_{0.035} \mathrm{Ga}_{0.965} \mathrm{~N}$ cladding layers was $8.2 \mathrm{~cm}^{-1}$, which was $2.3 \mathrm{~cm}^{-1}$ lower than that of conventional LD sample. This reduction in internal loss was not so significant to account for the reduction of the threshold current density and the increase in the slope efficiency. From our previous report, the improvement of ITO LDs with a $\mathrm{p}-\mathrm{Al}_{0.035} \mathrm{Ga}_{0.965} \mathrm{~N}$ cladding layer was attributed to the reduced non-radiative recombination centers of QWs and increasing hole concentration and injection efficiency [29]. Fig. 17b shows a comparison of $I-V$ curves for ITO LDs and conventional LD under CW electrical injection. With a decrease of p-AlGaN cladding layer thickness and Al-content, the LD operation voltages decreased. The operation voltage of the ITO LD with the $300 \mathrm{~nm} \mathrm{p-}$ $\mathrm{Al}_{0.035} \mathrm{Ga}_{0.965} \mathrm{~N}$ cladding layer was $0.6 \mathrm{~V}$ lower than that of the conventional $\mathrm{LD}$ at a current density of $4 \mathrm{kA} \mathrm{cm}^{-2}$, which was attributed to the reduced series resistance due to reduced thickness and Al-content of p-AlGaN cladding

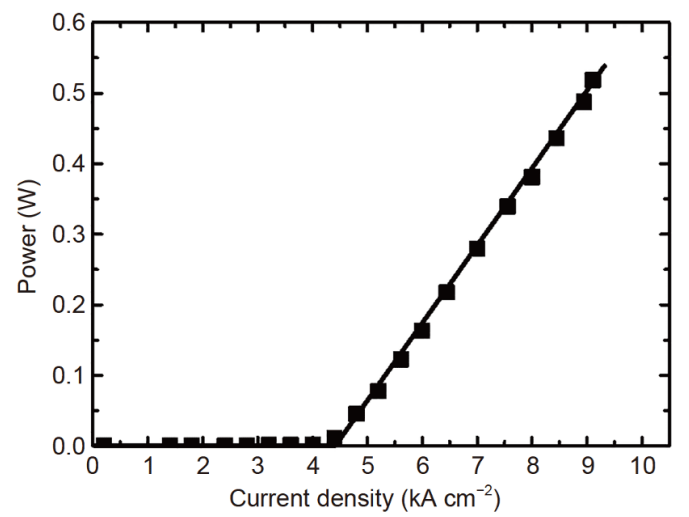

Figure $18 P$ - $I$ curve of ITO LDs with a $300 \mathrm{~nm} \mathrm{p}-\mathrm{Al}_{0.035} \mathrm{Ga}_{0.965} \mathrm{~N}$ cladding layer. The front facet coating was $40 \%$. 
layer.

Because the threshold current density of the ITO LD with a $\mathrm{p}-\mathrm{Al}_{0.035} \mathrm{Ga}_{0.965} \mathrm{~N}$ cladding layer was as low as $1.6 \mathrm{kA} \mathrm{cm}^{-2}$, it enabled a reduction in the front facet coating reflectivity to $40 \%$, and an increase in the ridge size to $15 \mu \mathrm{m}$ wide and $1200 \mu \mathrm{m}$ long. The $P$-I curve of the ITO LDs was measured under pulsed operation as shown in Fig. 18. The threshold current density was $4.4 \mathrm{kA} \mathrm{cm}^{-2}$ and the slope efficiency was $0.62 \mathrm{~W} \mathrm{~A}^{-1}$. The output power was as high as $500 \mathrm{~mW}$ at the current density of $9 \mathrm{kA} \mathrm{cm}^{-2}$, which was typical for GaN-based green LDs.

\section{CONCLUSIONS}

In summary, the challenges and progress of GaN-based blue and green LDs were reviewed from the aspects of epitaxial growth and layer structure design. Due to large differences in lattice constants and growth conditions among InN, GaN, and AlN, much effort must still be made to improve the quality of InGaN MQW gain medium for blue and especially green LDs. The p-type doping profile, conditions and layer structure are critical for the reduction of internal losses and also to mitigate the degradation of InGaN MQWs. In addition, hole injection is a key issue for GaN-based LDs.

\section{Received 21 January 2020; accepted 21 February 2020; published online 18 March 2020}

1 Nakamura S. The roles of structural imperfections in InGaNbased blue light-emitting diodes and laser diodes. Science, 1998, 281: 956-961

2 Ponce FA, Bour DP. Nitride-based semiconductors for blue and green light-emitting devices. Nature, 1997, 386: 351-359

3 Akasaki I, Amano H. Crystal growth and conductivity control of group III nitride semiconductors and their application to short wavelength light emitters. Jpn J Appl Phys, 1997, 36: 5393-5408

4 DenBaars SP, Feezell D, Kelchner K, et al. Development of gallium-nitride-based light-emitting diodes (LEDs) and laser diodes for energy-efficient lighting and displays. Acta Mater, 2013, 61: 945-951

5 Wierer Jr JJ, Tsao JY, Sizov DS. Comparison between blue lasers and light-emitting diodes for future solid-state lighting. Laser Photonics Rev, 2013, 7: 963-993

6 Queren D, Avramescu A, Brüderl G, et al. $500 \mathrm{~nm}$ electrically driven InGaN based laser diodes. Appl Phys Lett, 2009, 94: 081119

7 Schwarz UT, Scheibenzuber WG. The green laser diode: completing the rainbow. Optics Photonics News, 2011, 22: 38-44

8 Jansen M, Cantos BD, Carey GP, et al. Visible laser and laser array sources for projection display. Proc SPIE, 2006, 6135: $61350 \mathrm{~T}$

9 Lutgen S, Avramescu A, Lermer T, et al. Progress of blue and green InGaN laser diodes. Proc SPIE, 2010, 7616: 76160G

10 Sizov D, Bhat R, Zah CE. Gallium indium nitride-based green lasers. J Lightwave Technol, 2012, 30: 679-699

11 Lingrong J, Jianping L, Aiqin T, et al. GaN-based green laser diodes. J Semicond, 2016, 37: 111001

12 Ambacher O. Growth and applications of group III-nitrides. J Phys D-Appl Phys, 1998, 31: 2653-2710

13 Kozaki T, Matsumura H, Sugimoto Y, et al. High-power and wide wavelength range GaN-based laser diodes. Proc SPIE, 2006, 6133: 613306

14 Amano H. Development of GaN-based blue LEDs and metalorganic vapor phase epitaxy of GaN and related materials. Prog Cryst Growth Charact Mater, 2016, 62: 126-135

15 Nakamura S, Senoh M, Nagahama S, et al. Blue InGaN-based laser diodes with an emission wavelength of $450 \mathrm{~nm}$. Appl Phys Lett, 2000, 76: 22-24

16 Nagahama S, Yanamoto T, Sano M, et al. Wavelength dependence of InGaN laser diode characteristics. Jpn J Appl Phys, 2001, 40: 3075-3081

17 Kozaki T, Yanamoto T, Miyoshi T, et al. 52.3: High-power InGaN blue-laser diodes for displays. SID Symposium Digest, 2005, 36: 1605-1607

18 Miyoshi T, Kozaki T, Yanamoto T, et al. GaN-based high-outputpower blue laser diodes for display applications. J Soc Inf Display, 2007, 15: 157

19 Miyoshi T, Kozaki T, Yanamoto T, et al. 63.3: GaN-based 1-W continuous-wave blue-laser diodes. SID Symposium Digest, 2008, 39: 966

20 Nakatsu Y, Nagao Y, Kozuru K, et al. High-efficiency blue and green laser diodes for laser displays. Proc SPIE, 2019, 10918: $10918 \mathrm{D}$

21 Liu J, Zhang L, Li D, et al. GaN-based blue laser diodes with $2.2 \mathrm{~W}$ of light output power under continuous-wave operation. IEEE Photon Technol Lett, 2017, 29: 2203-2206

$22 \mathrm{Hu} \mathrm{L}$, Zhang LQ, Liu JP, et al. High power GaN-based blue laser diodes. Chin J Lasers, 2020, 47: 0701004

23 Avramescu A, Lermer T, Müller J, et al. True green laser diodes at $524 \mathrm{~nm}$ with $50 \mathrm{~mW}$ continuous wave output power on $c$-plane GaN. Appl Phys Express, 2010, 3: 061003

24 Miyoshi T, Masui S, Okada T, et al. 510-515 nm InGaN-based green laser diodes on $c$-plane GaN substrate. Appl Phys Express, 2009, 2: 062201

25 Miyoshi T, Masui S, Okada T, et al. InGaN-based 518 and $488 \mathrm{~nm}$ laser diodes on $c$-plane GaN substrate. Phys Status Solidi A, 2010, 207: 1389-1392

26 Tian A, Liu J, Zhang L, et al. Optical characterization of InGaN/ GaN quantum well active region of green laser diodes. Appl Phys Express, 2017, 10: 012701

27 Tian A, Liu J, Zhang L, et al. Significant increase of quantum efficiency of green InGaN quantum well by realizing step-flow growth. Appl Phys Lett, 2017, 111: 112102

28 Tian A, Liu J, Zhang L, et al. Green laser diodes with low operation voltage obtained by suppressing carbon impurity in AlGaN:Mg cladding layer. Phys Status Solidi C, 2016, 13: 245-247

29 Hu L, Ren X, Liu J, et al. High-power hybrid GaN-based green laser diodes with ITO cladding layer. Photon Res, 2020, 8: 279

30 Sizov D, Bhat R, Heberle A, et al. True-green (11-22) plane optically pumped laser with cleaved $m$-plane facets. Appl Phys Lett, 2011, 99: 041117

31 Huang CY, Hardy MT, Fujito K, et al. Demonstration of $505 \mathrm{~nm}$ laser diodes using wavelength-stable semipolar $202 \overline{1}$ InGaN/GaN quantum wells. Appl Phys Lett, 2011, 99: 241115 
32 Enya $\mathrm{Y}$, Yoshizumi $\mathrm{Y}$, Kyono $\mathrm{T}$, et al. $531 \mathrm{~nm}$ green lasing of InGaN based laser diodes on semi-polar $20 \overline{2} 1$ free-standing GaN substrates. Appl Phys Express, 2009, 2: 082101

33 Takagi S, Enya Y, Kyono T, et al. High-power (over $100 \mathrm{~mW}$ ) green laser diodes on semipolar $20 \overline{2} 1 \mathrm{GaN}$ substrates operating at wavelengths beyond $530 \mathrm{~nm}$. Appl Phys Express, 2012, 5: 082102

34 Yanashima $\mathrm{K}$, Nakajima $\mathrm{H}$, Tasai $\mathrm{K}$, et al. Long-lifetime true green laser diodes with output power over $50 \mathrm{~mW}$ above $525 \mathrm{~nm}$ grown on semipolar $20 \overline{2} 1 \mathrm{GaN}$ substrates. Appl Phys Express, 2012, 5: 082103

35 Khan A. Laser diodes go green. Nat Photon, 2009, 3: 432-434

36 Chen G, Craven M, Kim A, et al. Performance of high-power IIInitride light emitting diodes. Phys Status Solidi A, 2008, 205: 1086-1092

37 Morkoc H. Handbook of Nitride Semiconductors and Devices. Weinheim: Wiley-VCH Verlag GmbH \& Co. KGaA, 2008

38 Morishita Y, Nomura Y, Goto S, et al. Effect of hydrogen on the surface-diffusion length of $\mathrm{Ga}$ adatoms during molecular-beam epitaxy. Appl Phys Lett, 1995, 67: 2500-2502

39 Lermer T, Gomez-Iglesias A, Sabathil M, et al. Gain of blue and cyan InGaN laser diodes. Appl Phys Lett, 2011, 98: 021115

40 Queren D, Schillgalies M, Avramescu A, et al. Quality and thermal stability of thin InGaN films. J Cryst Growth, 2009, 311: 2933-2936

41 Strauß U, Avramescu A, Lermer T, et al. Pros and cons of green InGaN laser on $c$-plane GaN. Phys Status Solidi B, 2011, 248: 652-657

42 Queren D, Avramescu A, Schillgalies M, et al. Epitaxial design of $475 \mathrm{~nm}$ InGaN laser diodes with reduced wavelength shift. Phys Status Solidi C, 2009, 6: S826-S829

43 Li Z, Liu J, Feng M, et al. Suppression of thermal degradation of InGaN/GaN quantum wells in green laser diode structures during the epitaxial growth. Appl Phys Lett, 2013, 103: 152109

44 Liu J, Li Z, Zhang L, et al. Realization of InGaN laser diodes above $500 \mathrm{~nm}$ by growth optimization of the InGaN/GaN active region. Appl Phys Express, 2014, 7: 111001

45 Yang J, Zhao DG, Jiang DS, et al. Emission efficiency enhanced by reducing the concentration of residual carbon impurities in InGaN/GaN multiple quantum well light emitting diodes. Opt Express, 2016, 24: 13824

46 Follstaedt DM, Lee SR, Allerman AA, et al. Strain relaxation in AlGaN multilayer structures by inclined dislocations. J Appl Phys, 2009, 105: 083507

47 Li J, Oder TN, Nakarmi ML, et al. Optical and electrical properties of Mg-doped p-type $\mathrm{Al}_{x} \mathrm{Ga}_{1-x} \mathrm{~N}$. Appl Phys Lett, 2002, 80: 1210-1212

48 Tian A, Liu J, Ikeda M, et al. Conductivity enhancement in AlGaN:Mg by suppressing the incorporation of carbon impurity. Appl Phys Express, 2015, 8: 051001

49 Kuramoto M, Sasaoka C, Futagawa N, et al. Reduction of internal loss and threshold current in a laser diode with a ridge by selective re-growth (RiS-LD). Phys Status Solidi A, 2002, 192: 329334

50 Schmidt O, Wolst O, Kneissl $\mathrm{M}$, et al. Gain and photoluminescence spectroscopy in violet and ultraviolet InAlGaN laser structures. Phys Status Solidi C, 2005, 2: 2891-2894

51 Kioupakis E, Rinke P, Schleife A, et al. Free-carrier absorption in nitrides from first principles. Phys Rev B, 2010, 81: 241201

52 Kioupakis E, Rinke P, Van de Walle CG. Determination of internal loss in nitride lasers from first principles. Appl Phys Ex- press, 2010, 3: 082101

53 David A, Grundmann MJ, Kaeding JF, et al. Carrier distribution in (0001)InGaN/GaN multiple quantum well light-emitting diodes. Appl Phys Lett, 2008, 92: 053502

54 Meyaard DS, Lin GB, Shan Q, et al. Asymmetry of carrier transport leading to efficiency droop in GaInN based lightemitting diodes. Appl Phys Lett, 2011, 99: 251115

55 Wang $\mathrm{CH}$, Chang SP, $\mathrm{Ku} \mathrm{PH}$, et al. Hole transport improvement in InGaN/GaN light-emitting diodes by graded-composition multiple quantum barriers. Appl Phys Lett, 2011, 99: 171106

56 Yeo YC, Chong TC, Li MF. Electronic band structures and effective-mass parameters of wurtzite GaN and InN. J Appl Phys, 1998, 83: 1429-1436

57 Ikeda M, Zhang F, Zhou R, et al. Thermionic emission of carriers in InGaN/(In)GaN multiple quantum wells. Jpn J Appl Phys, 2019, 58: SCCB03

58 Liu JP, Ryou JH, Dupuis RD, et al. Barrier effect on hole transport and carrier distribution in $\mathrm{InGaN} / \mathrm{GaN}$ multiple quantum well visible light-emitting diodes. Appl Phys Lett, 2008, 93: 021102

59 Zhou K, Ikeda M, Liu J, et al. Remarkably reduced efficiency droop by using staircase thin InGaN quantum barriers in InGaN based blue light emitting diodes. Appl Phys Lett, 2014, 105: 173510

60 Cho YH, Gainer GH, Fischer AJ, et al. "S-shaped" temperaturedependent emission shift and carrier dynamics in InGaN/GaN multiple quantum wells. Appl Phys Lett, 1998, 73: 1370-1372

61 Bai J, Wang T, Sakai S. Influence of the quantum-well thickness on the radiative recombination of InGaN/GaN quantum well structures. J Appl Phys, 2000, 88: 4729-4733

62 Seo Im J, Kollmer H, Off J, et al. Reduction of oscillator strength due to piezoelectric fields in $\mathrm{GaNAl}_{x} \mathrm{Ga}_{1-x} \mathrm{~N}$ quantum wells. Phys Rev B, 1998, 57: R9435-R9438

63 Peng LH, Chuang CW, Lou LH. Piezoelectric effects in the optical properties of strained InGaN quantum wells. Appl Phys Lett, 1999, 74: 795-797

64 Chang SJ, Lai WC, Su YK, et al. InGaN-GaN multi-quantum-well blue and green light-emitting diodes. IEEE J Sel Top Quantum Electron, 2002, 8: 278-283

65 Wang T, Bai J, Sakai S, et al. Investigation of the emission mechanism in InGaN/GaN-based light-emitting diodes. Appl Phys Lett, 2001, 78: 2617-2619

66 Bernardini F, Fiorentini V, Vanderbilt D. Spontaneous polarization and piezoelectric constants of III-V nitrides. Phys Rev B, 1997, 56: R10024-R10027

67 Bernardini F, Fiorentini V. Polarization fields in nitride nanostructures: 10 points to think about. Appl Surf Sci, 2000, 166: 2329

68 Zhang M, Moore J, Mi Z, et al. Polarization effects in self-organized InGaN/GaN quantum dots grown by RF-plasma-assisted molecular beam epitaxy. J Cryst Growth, 2009, 311: 2069-2072

69 Della Sala F, Di Carlo A, Lugli P, et al. Free-carrier screening of polarization fields in wurtzite GaN/InGaN laser structures. Appl Phys Lett, 1999, 74: 2002-2004

70 Huang CY, Lin YD, Tyagi A, et al. Optical waveguide simulations for the optimization of InGaN-based green laser diodes. J Appl Phys, 2010, 107: 023101

71 Adachi M, Yoshizumi Y, Enya Y, et al. Low threshold current density InGaN based $520-530 \mathrm{~nm}$ green laser diodes on semipolar $20 \overline{2} 1$ free-standing GaN substrates. Appl Phys Express, 2010, 3: 121001 
72 Hardy MT, Wu F, Shan Hsu P, et al. True green semipolar InGaN-based laser diodes beyond critical thickness limits using limited area epitaxy. J Appl Phys, 2013, 114: 183101

73 Lin YD, Yamamoto S, Huang CY, et al. High quality InGaN/ AlGaN multiple quantum wells for semipolar InGaN green laser diodes. Appl Phys Express, 2010, 3: 082001

74 Wu F, Lin YD, Chakraborty A, et al. Stacking fault formation in the long wavelength $\mathrm{InGaN} / \mathrm{GaN}$ multiple quantum wells grown on $m$-plane GaN. Appl Phys Lett, 2010, 96: 231912

75 Feng MX, Liu JP, Zhang SM, et al. Design considerations for GaN-based blue laser diodes with InGaN upper waveguide layer. IEEE J Sel Top Quantum Electron, 2013, 19: 1500705

76 Hager T, Brüderl G, Lermer T, et al. Current dependence of electro-optical parameters in green and blue (AlIn)GaN laser diodes. Appl Phys Lett, 2012, 101: 171109

77 Nakamura S. InGaN-based blue laser diodes. IEEE J Sel Top Quantum Electron, 1997, 3: 712-718

78 Farrell RM, Haeger DA, Hsu PS, et al. Determination of internal parameters for AlGaN-cladding-free $m$-plane InGaN/GaN laser diodes. Appl Phys Lett, 2011, 99: 171115

79 Becerra DL, Kuritzky LY, Nedy J, et al. Measurement and analysis of internal loss and injection efficiency for continuous-wave blue semipolar $20 \overline{2} \overline{1}$ III-nitride laser diodes with chemically assisted ion beam etched facets. Appl Phys Lett, 2016, 108: 091106

80 Ryu HY, Ha KH, Son JK, et al. Determination of internal parameters in blue InGaN laser diodes by the measurement of cavitylength dependent characteristics. Appl Phys Lett, 2008, 93: 011105

81 Kawaguchi M, Imafuji O, Nozaki S, et al. Optical-loss suppressed InGaN laser diodes using undoped thick waveguide structure. Proc SPIE, 2016, 9748: 974818

82 Duff AI, Lymperakis L, Neugebauer J. Understanding and controlling indium incorporation and surface segregation on $\mathrm{In}_{x} \mathrm{Ga}_{1-x} \mathrm{~N}$ surfaces: An ab initio approach. Phys Rev B, 2014, 89: 085307

83 Stringfellow GB. Microstructures produced during the epitaxial growth of InGaN alloys. J Cryst Growth, 2010, 312: 735-749

84 Tian A, Liu J, Zhang L, et al. Green laser diodes with low threshold current density via interface engineering of InGaN/ GaN quantum well active region. Opt Express, 2017, 25: 415

85 Oliver RA, Kappers MJ, Humphreys CJ, et al. Growth modes in heteroepitaxy of InGaN on GaN. J Appl Phys, 2005, 97: 013707

86 Oliver RA, Kappers MJ, Humphreys CJ, et al. The influence of ammonia on the growth mode in InGaN/GaN heteroepitaxy. J Cryst Growth, 2004, 272: 393-399

87 Florescu DI, Ting SM, Merai VN, et al. InGaN quantum well epilayers morphological evolution under a wide range of MOCVD growth parameter sets. Phys Status Solidi C, 2006, 3: 1811-1814

88 Falta J, Schmidt T, Gangopadhyay S, et al. Cleaning and growth morphology of GaN and InGaN surfaces. Phys Status Solidi B, 2011, 248: 1800-1809

89 Kadir A, Meissner C, Schwaner T, et al. Growth mechanism of InGaN quantum dots during metalorganic vapor phase epitaxy. J Cryst Growth, 2011, 334: 40-45

90 Pristovsek M, Kadir A, Meissner C, et al. Growth mode transition and relaxation of thin InGaN layers on GaN (0001). J Cryst Growth, 2013, 372: 65-72

91 Massabuau FCP, Davies MJ, Oehler F, et al. The impact of trench defects in InGaN/GaN light emitting diodes and implications for the "green gap" problem. Appl Phys Lett, 2014, 105: 112110

92 Massabuau FCP, Sahonta SL, Trinh-Xuan L, et al. Morphological, structural, and emission characterization of trench defects in InGaN/GaN quantum well structures. Appl Phys Lett, 2012, 101: 212107

93 Massabuau FCP, Trinh-Xuan L, Lodié D, et al. Correlations between the morphology and emission properties of trench defects in InGaN/GaN quantum wells. J Appl Phys, 2013, 113: 073505

94 Tian A, Liu J, Zhou R, et al. Green laser diodes with constant temperature growth of InGaN/GaN multiple quantum well active region. Appl Phys Express, 2019, 12: 064007

95 Jiang F, Zhang J, Xu L, et al. Efficient InGaN-based yellow-lightemitting diodes. Photon Res, 2019, 7: 144

96 Funato M, Kim YS, Hira T, et al. Remarkably suppressed luminescence inhomogeneity in a (0001) InGaN green laser structure. Appl Phys Express, 2013, 6: 111002

97 Saito S, Hashimoto R, Hwang J, et al. InGaN light-emitting diodes on $c$-face sapphire substrates in green gap spectral range. Appl Phys Express, 2013, 6: 111004

98 Yamamoto S, Zhao Y, Pan CC, et al. High-efficiency singlequantum-well green and yellow-green light-emitting diodes on semipolar $20 \overline{2} 1 \mathrm{GaN}$ substrates. Appl Phys Express, 2010, 3: 122102

99 Chung RB, Lin YD, Koslow I, et al. Electroluminescence characterization of $20 \overline{2} 1 \mathrm{InGaN} / \mathrm{GaN}$ light emitting diodes with various wavelengths. Jpn J Appl Phys, 2010, 49: 070203

100 Yang J, Zhao DG, Jiang DS, et al. Investigation on the compensation effect of residual carbon impurities in low temperature grown Mg doped GaN films. J Appl Phys, 2014, 115: 163704

101 Koleske DD, Wickenden AE, Henry RL, et al. Influence of MOVPE growth conditions on carbon and silicon concentrations in GaN. J Cryst Growth, 2002, 242: 55-69

102 Parish G, Keller S, Denbaars SP, et al. SIMS investigations into the effect of growth conditions on residual impurity and silicon incorporation in $\mathrm{GaN}$ and $\mathrm{Al}_{x} \mathrm{Ga}_{1-x} \mathrm{~N}$. J Elec Materi, 2000, 29: 15-20

103 Chen JT, Forsberg U, Janzén E. Impact of residual carbon on twodimensional electron gas properties in $\mathrm{Al}_{x} \mathrm{Ga}_{1-x} \mathrm{~N} / \mathrm{GaN}$ heterostructure. Appl Phys Lett, 2013, 102: 193506

104 Jiang L, Liu J, Tian A, et al. Influence of substrate misorientation on carbon impurity incorporation and electrical properties of p$\mathrm{GaN}$ grown by metalorganic chemical vapor deposition. Appl Phys Express, 2019, 12: 055503

105 Monavarian M, Rashidi A, Feezell D. A decade of nonpolar and semipolar III-nitrides: A review of successes and challenges. Phys Status Solidi A, 2018, 216: 1800628

106 Weng GE, Zhao WR, Chen SQ, et al. Strong localization effect and carrier relaxation dynamics in self-assembled InGaN quantum dots emitting in the green. Nanoscale Res Lett, 2015, 10: 31

107 Li ZC, Liu JP, Feng MX, et al. Effects of matrix layer composition on the structural and optical properties of self-organized InGaN quantum dots. J Appl Phys, 2013, 114: 093105

108 Mei Y, Weng GE, Zhang BP, et al. Quantum dot vertical-cavity surface-emitting lasers covering the 'green gap'. Light Sci Appl, 2017, 6: e16199

109 Qi W, Zhang J, Mo C, et al. Effects of thickness ratio of InGaN to $\mathrm{GaN}$ in superlattice strain relief layer on the optoelectrical properties of InGaN-based green LEDs grown on Si substrates. J Appl Phys, 2017, 122: 084504

110 Shioda T, Yoshida H, Tachibana K, et al. Enhanced light output power of green LEDs employing AlGaN interlayer in InGaN/GaN 
MQW structure on sapphire (0001) substrate. Phys Status Solidi A, 2012, 209: 473-476

111 Alhassan AI, Farrell RM, Saifaddin B, et al. High luminous efficacy green light-emitting diodes with AlGaN cap layer. Opt Express, 2016, 24: 17868

112 Zhao Y, Fu H, Wang GT, et al. Toward ultimate efficiency: progress and prospects on planar and $3 \mathrm{D}$ nanostructured nonpolar and semipolar InGaN light-emitting diodes. Adv Opt Photon, 2018, 10: 246

113 Kuc M, Piskorski L, Sokół AK, et al. Optical simulations of blue and green semipolar InGaN/GaN lasers. Proc SPIE, 2018, 10532: 1053228

114 Boycheva S, Sytchkova AK, Piegari A. Optical and electrical characterization of r.f. sputtered ITO films developed as art protection coatings. Thin Solid Films, 2007, 515: 8474-8478

115 Wen AJC, Chen KL, Yang MH, et al. Effect of substrate angle on properties of ITO films deposited by cathodic arc ion plating with In-Sn alloy target. Surf Coatings Tech, 2005, 198: 362-366

116 Hardy MT, Holder CO, Feezell DF, et al. Indium-tin-oxide clad blue and true green semipolar InGaN/GaN laser diodes. Appl Phys Lett, 2013, 103: 081103

117 Margalith T, Buchinsky O, Cohen DA, et al. Indium tin oxide contacts to gallium nitride optoelectronic devices. Appl Phys Lett, 1999, 74: 3930-3932

118 Liu H, Avrutin V, Izyumskaya N, et al. Transparent conducting oxides for electrode applications in light emitting and absorbing devices. Superlattices MicroStruct, 2010, 48: 458-484

119 Myzaferi A, Reading AH, Cohen DA, et al. Transparent conducting oxide clad limited area epitaxy semipolar III-nitride laser diodes. Appl Phys Lett, 2016, 109: 061109

120 Mehari S, Cohen DA, Becerra DL, et al. Demonstration of enhanced continuous-wave operation of blue laser diodes on a semipolar $20 \overline{2} \overline{1} \mathrm{GaN}$ substrate using indium-tin-oxide/thin-pGaN cladding layers. Opt Express, 2018, 26: 1564

Acknowledgements This work was financially supported by the National Key Research and Development Program of China (2016YFB0401803, 2017YFE0131500 and 2017YFB0405000), National Natural Science Foundation of China (61834008, 61574160, 61804164, and 61704184), Natural Science Foundation of Jiangsu province (BK20180254), China Postdoctoral Science Foundation (2018M630619). We are thankful to the technical support from Nano Fabrication Facility, Platform for Characterization \& Test, and Nano-X of SINANO, CAS.

Author contributions Liu J proposed the topic and the outline of the manuscript, and wrote the introduction and the challenges section. Tian $\mathrm{A}$ and $\mathrm{Hu} \mathrm{L}$ wrote the other sections under the direction of Liu J. All authors contributed to the discussion of the manuscript.

Conflict of interest The authors declare that they have no conflicts of interest.

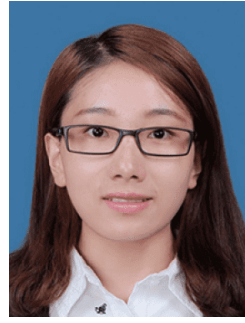

Aiqin Tian is a postdoctoral researcher in Suzhou Institute of Nano-Tech and Nano-Bionics, Chinese Academy of Sciences (CAS). She earned her doctoral degree from the University of Chinese Academy of Sciences in 2017. Her research focuses on MOCVD growth of III-nitride materials and devices.

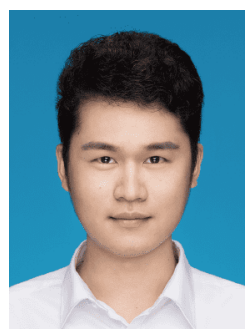

Lei $\mathrm{Hu}$ is a $\mathrm{PhD}$ candidate at the School of NanoTech and Nano-Bionics, University of Science and Technology of China. He received his $\mathrm{Ba}$ chelor degree (2016) from Soochow University. His research focuses on the fabrication and characterizations of GaN-based blue and green laser diodes.

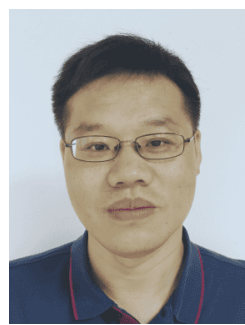

Jianping Liu is a professor at Suzhou Institute of Nano-Tech and Nano-Bionics, CAS. He earned his doctoral degree from the Institute of Semiconductors, CAS in 2004. He worked at the Lab of Optoelectronics Technology at Beijing University of Technology from 2004 to 2006 . He did postdoctoral research in the Department of Electrical Engineering at Georgia Institute of Technology from 2006 to 2010. His research interests include MOCVD growth, GaN-based materials and devices.

\section{GaN基蓝光与绿光激光器}

田爱琴 ${ }^{1 \dagger}$, 胡否 ${ }^{1,2 \dagger}$, 张立群 ${ }^{1}$, 刘建平 ${ }^{1,2^{*}}$, 杨辉 ${ }^{1,2}$

摘要 $\mathrm{GaN}$ 基激光二极管( $\mathrm{LD}$ )将半导体 $\mathrm{LD}$ 的波长扩展到可见光谱 和紫外光谱范围, 因此有望被广泛用于光钟等量子技术、生物医 疗仪器、激光显示、照明和材料加工等领域. 尽管它们与 $\mathrm{GaN}$ 基 发光二极管(LED)基于相同的III氮化物材料, 但是蓝光和绿光 LD 面临更大的挑战. 在本文中, 我们从外延生长和结构设计的角度对 $\mathrm{GaN}$ 基蓝光和绿光 $\mathrm{LD}$ 面临的挑战和进展进行了回顾总结. InN、 $\mathrm{GaN}$ 和AlN之间的晶格常数和生长条件差异很大, 因此需要进行深 入研究来提高蓝光, 尤其是绿光 $L D$ 的InGaN/GaN多量子阱(MQW) 增益介质的材料质量. $\mathrm{p}$ 型掺杂分布, 生长条件和器件结构对减少 内部损耗并抑制InGaN MQW的热退化至关重要. 此外, 空穴注入 也是 $\mathrm{GaN}$ 基 $\mathrm{LD}$ 面临的关键问题. 